University of Wollongong

Research Online

Faculty of Engineering and Information

Faculty of Engineering and Information

Sciences - Papers: Part B

Sciences

2017

\title{
Strain-induced ferrite formation and its effect on mechanical properties of a dual phase steel produced using laboratory simulated strip casting
}

Zhiping Xiong

University of Wollongong, zx868@uowmail.edu.au

Ahmed A. Saleh

University of Wollongong, asaleh@uow.edu.au

Andrii Kostryzhev

University of Wollongong, andrii@uow.edu.au

Elena V. Pereloma

University of Wollongong, elenap@uow.edu.au

Follow this and additional works at: https://ro.uow.edu.au/eispapers1

Part of the Engineering Commons, and the Science and Technology Studies Commons

Research Online is the open access institutional repository for the University of Wollongong. For further information contact the UOW Library: research-pubs@uow.edu.au 


\title{
Strain-induced ferrite formation and its effect on mechanical properties of a dual phase steel produced using laboratory simulated strip casting
}

\author{
Abstract \\ Thermo-mechanical processing of a strip cast dual phase (DP) steel was carried out using a Gleeble \\ thermo-mechanical simulator. The effect of deformation temperatures in the range from 1050 to $700{ }^{\circ} \mathrm{C}$ \\ on the microstructure evolution was investigated using optical, scanning and transmission electron \\ microscopy along with electron backscattering diffraction (EBSD). Strain-induced ferrite (SIF) formation \\ was observed following austenite deformation ( $\sim 0.41$ reduction) in the $800-700^{\circ} \mathrm{C}$ temperature range, \\ leading to a ferrite grain refinement down to $3.1 \pm 2.3 \mu \mathrm{m}$. A novel segmentation procedure was applied to \\ separate selected EBSD maps into polygonal ferrite, SIF and second phase regions (bainite/martensite). \\ Following this, the microtexture, misorientation angle distribution and the deviation from the \\ Kurdjumov-Sachs and Nishiyama-Wasserman orientation relationships of each microstructure \\ constituent were analysed. Based on iso-work modelling analysis of tensile stress-strain curves, the SIF \\ was found to enhance strength with a slight decrease in ductility compared to polygonal ferrite. The \\ tensile mechanical properties after deformation at $750^{\circ} \mathrm{C}$ reached the level of DP 600 produced in \\ industry, highlighting the potential to manufacture DP steels via the strip casting technique.
}

\section{Keywords}

dual, properties, mechanical, effect, laboratory, its, produced, strip, steel, phase, simulated, strain-induced, ferrite, formation, casting

\section{Disciplines \\ Engineering | Science and Technology Studies}

\section{Publication Details}

Xiong, Z. P., Saleh, A. A., Kostryzhev, A. G. \& Pereloma, E. V. (2017). Strain-induced ferrite formation and its effect on mechanical properties of a dual phase steel produced using laboratory simulated strip casting. Journal of Alloys and Compounds, 721 291-306. 


\title{
Strain-induced ferrite formation and its effect on mechanical properties of a dual phase steel produced using laboratory simulated strip casting
}

\author{
Z.P. Xiong ${ }^{1 *}$, A.A. Saleh ${ }^{1}$, A.G. Kostryzhev ${ }^{1}$, E.V. Pereloma ${ }^{1,2}$ \\ ${ }^{1}$ School of Mechanical, Materials and Mechatronic Engineering, University of Wollongong, \\ Wollongong, NSW 2522, Australia \\ ${ }^{2}$ Electron Microscopy Centre, University of Wollongong, Wollongong, NSW 2519, Australia
}

Abstract: Thermo-mechanical processing of a strip cast dual phase (DP) steel was carried out using a Gleeble thermo-mechanical simulator. The effect of deformation temperatures in the range from 1050 to $700{ }^{\circ} \mathrm{C}$ on the microstructure evolution was investigated using optical, scanning and transmission electron microscopy along with electron backscattering diffraction (EBSD). Strain-induced ferrite (SIF) formation was observed following austenite deformation ( 0.41 reduction) in the $800-700{ }^{\circ} \mathrm{C}$ temperature range, leading to a ferrite grain refinement down to $3.1 \pm 2.3 \mu \mathrm{m}$. A novel segmentation procedure was applied to separate selected EBSD maps into polygonal ferrite, SIF and second phase regions (bainite/martensite). Following this, the microtexture, misorientation angle distribution and the deviation from the Kurdjumov-Sachs and Nishiyama-Wasserman orientation relationships of each microstructure constituent were analysed. Based on iso-work modelling analysis of tensile stress-strain curves, the SIF was found to enhance strength with a slight decrease in ductility compared to polygonal ferrite. The tensile mechanical properties after deformation at $750{ }^{\circ} \mathrm{C}$ reached the level of DP 600 produced in industry, highlighting the potential to manufacture DP steels via the strip casting technique.

Keywords: Dual phase steel; Deformation temperature; Strain-induced ferrite; Diffusional transformation; EBSD.

*Correspondence author email address: zx868@uowmail.edu.au (Z.P. Xiong) 


\section{Introduction}

Ferrite-martensite dual phase (DP) steels (hereafter referred to DP steel) are widely studied because of their simultaneously high strength and ductility, which satisfy the requirement of car weight reduction and fuel saving in the automotive industry [1-3]. DP steels are typically produced commercially via hot rolling and cold rolling followed by annealing [1, 2]. Another potentially competitive technology for commercial production of DP steels is the strip casting process, wherein strips are directly obtained from molten metal, followed by a subsequent rolling [4-6]. In this regard, the strip casting process has been successfully used for industrial production of carbon steels, stainless steels and silicon steels [6, 7] as well as laboratory production of twinning-induced plasticity steel [8]. In addition, the present authors have undertaken laboratory scale trials to produce transformation-induced plasticity steel [9] and DP steel $[10,11]$, and their microstructures and mechanical properties were analysed in detail. Although the microstructure and textures of austenitic strip cast steels containing two phases were investigated earlier [12], this is one of the first studies addressing the formation of ferrite-martensite DP steels using laboratory simulated strip casting. It should be noted that the coarse prior austenite grain size (PAGS) remains a primary challenge on the way of obtaining optimal mechanical properties via the strip casting technology due to limited deformation resulting from only one mill stand in this processing [6]. Thus, studying on the effect of deformation temperature is significantly important.

Thermo-mechanical controlled processing (TMCP) is widely used in steel industry to tune and refine microstructures with deformation temperature being one of the key parameters in this process. Deformation above non-recrystallisation temperature $\left(T_{n r}\right)$ leads to austenite recrystallisation and in turn an increase in the number of polygonal ferrite nucleation sites, resulting in microstructure refinement $[13,14]$. When the deformation temperature is below 
$T_{n r}$, the microstructure is further refined due to the increased number of polygonal ferrite nucleation sites in the interior of the pancaked austenite grains [15, 16]. However, most commonly applied TMCP schedules can only achieve a minimum grain size of $\sim 5 \mu \mathrm{m}$ for carbon and alloyed steels [17].

Alternatively, advanced TMCP, such as strain-induced ferrite (SIF) formation [18] or warm rolling followed by intercritical annealing $[19,20]$, provides the possibility to reduce the grain size down to $\sim 1 \mu \mathrm{m}$. The SIF formation is attractive for future applications as it can be utilised for mass production on currently available industrial facilities or after minor modifications. When the deformation temperature is in the range from austenite-to-ferrite transformation start temperature $\left(\mathrm{Ar}_{3}\right)$ to $\left(\mathrm{Ar}_{3}+100\right){ }^{\circ} \mathrm{C}$, SIF transformation reduces the average ferrite grain size (considering both polygonal ferrite and SIF) to $1 \mu \mathrm{m}$ [21-22]. Hurley et al. [17, 23, 24] produced low carbon steels $(0.0022-0.17$ wt. \% C) with finegrained SIF, resulting in an average ferrite grain size of $1-3 \mu \mathrm{m}$. Karmakar et al. [22] and Mukherjee et al. [25] also successfully produced DP steels with an average ferrite grain size of $\sim 1.5 \mu \mathrm{m}$ by the application of SIF transformation.

The effects of deformation temperature, strain, strain rate and PAGS on SIF formation was systematically studied for DP steels [22, 25, 26]. SIF was found to preferentially nucleate along prior austenite grain boundaries, with in-grain nucleation promoted by a decrease in deformation temperature and an increase in strain, leading to more nucleation sites for SIF. Increasing the strain rate also increases the SIF nucleation sites, but reduces the time for its growth. Here increasing the SIF nucleation sites leads to a finer average ferrite grain size. 
All the above studies notwithstanding, the SIF transformation mechanism is not yet fully understood due to the complexities associated with its rapid formation during deformation and its subsequent evolution during cooling to room temperature [17, 27, 28]. For deformation temperatures between $A r_{3}$ and the equilibrium austenite-to-ferrite transformation start temperature $\left(\mathrm{Ae}_{3}\right)$, SIF formation was successfully simulated as diffusional transformation process in a $0.13 \mathrm{C}-0.19 \mathrm{Si}-0.49 \mathrm{Mn}$ steel (wt. \%), using the classical theory of ferrite nucleation and grain growth controlled by carbon diffusion [28, 29]. Alternatively, for deformation temperatures above the $A e_{3}$, SIF formation was suggested to occur via a diffusionless transformation accompanied with carbon diffusion during or after its growth in 0.06 - 0.79 C microalloyed steels (wt. \%) [27]. A massive transformation was also suggested for SIF formation in steels having a very low carbon content (0.0008 wt. \%) [30].

To this end, the present work investigates the effect of deformation temperature on ferrite formation during TMCP of strip cast DP steel using optical (OM), scanning (SEM) and transmission (TEM) electron microscopy, along with electron backscattering diffraction (EBSD). For the first time, ferrite grain refinement $(\sim 3 \mu \mathrm{m})$ was achieved via SIF formation in strip cast DP steel. Mechanical properties measured using tensile testing were comparable to commercially produced DP 600 steel. A novel segmentation procedure was developed to separate the EBSD maps into polygonal ferrite, SIF and second phase regions (bainite/martensite). The analysis of misorientation angle distributions, deviations from the Kurdjumov-Sachs (K-S) and Nishiyama-Wasserman (N-W) orientation relationships (ORs), and dislocation substructures of different microstructure constituents indicates a higher probability of SIF formation via a diffusional transformation mechanism rather than diffusionless transformation. 


\section{Experimental details}

Chemical composition of the studied steel was similar to conventional DP steels $[1,2]$ and contained 0.077 C, 0.81 Si, 1.47 Mn, 0.03 Al, 0.01 Cu, 0.23 Cr (wt. \%) and balance Fe. Ascast specimens of $36 \times 36 \mathrm{~mm}^{2}$ in plane and $1.2 \mathrm{~mm}$ thick were produced at Deakin University using a dip tester facility [31]. A copper substrate was immersed into molten steel for a short and controlled period of time, and then immediately lifted out to simulate the rapid solidification when liquid steel contacts the twin rolls in a strip caster [5].

The processing schedules (Fig. 1(a)) designed based on industrial strip casting production line, were carried out using a Gleeble 3500 thermo-mechanical simulator. Samples with $20 \times$ $15 \mathrm{~mm}^{2}$ in plane and $\sim 1 \mathrm{~mm}$ thick were cut from as-cast specimens. As the sample thickness was below the movement control capability of the Gleeble simulator, the investigated samples were sandwiched between two blocks of dummy samples $\left(20 \times 15 \times 2.5 \mathrm{~mm}^{3}\right.$; made of structural microalloyed steel) as shown in Fig. 1(b). The samples were heated at $40 \mathrm{Ks}^{-1}$ to $1000{ }^{\circ} \mathrm{C}$ to prevent any precipitation, then continuously heated at $20 \mathrm{Ks}^{-1}$ to $1300{ }^{\circ} \mathrm{C}$ in order to avoid temperature overshooting. Holding at $1300{ }^{\circ} \mathrm{C}$ for $180 \mathrm{~s}$ was employed to simulate the PAGS (117 $\pm 44 \mu \mathrm{m})$ resulting from dip casting [10]. The compositional segregation would be small in dip-cast sample due to rapid cooling [8] and not be significantly changed during this short austenitisation. After austenitisation, the samples were cooled at $30 \mathrm{Ks}^{-1}$ to the deformation temperatures, $T_{D}$ ranging from 1050 to $700{ }^{\circ} \mathrm{C}$, where deformation to $\sim 0.41$ reduction was applied at a strain rate of $0.5 \mathrm{~s}^{-1}$. This was followed by cooling at $10 \mathrm{Ks}^{-1}$ to $670{ }^{\circ} \mathrm{C}$ and water quenching to room temperature. At a cooling rate of $30 \mathrm{Ks}^{-1}$ without prior deformation the $\mathrm{Ar}_{3}$ was $695{ }^{\circ} \mathrm{C}$ [10]. Based on our previous study [10], cooling to $670{ }^{\circ} \mathrm{C}$ is expected to result in $0.5-0.9$ ferrite fraction depending on the deformation temperature. 
Hereafter, the samples deformed at $700,750,800,850,950$ and $1050{ }^{\circ} \mathrm{C}$ are referred to as DT 700, DT 750, DT 800, DT 850, DT 950 and DT 1050, respectively.

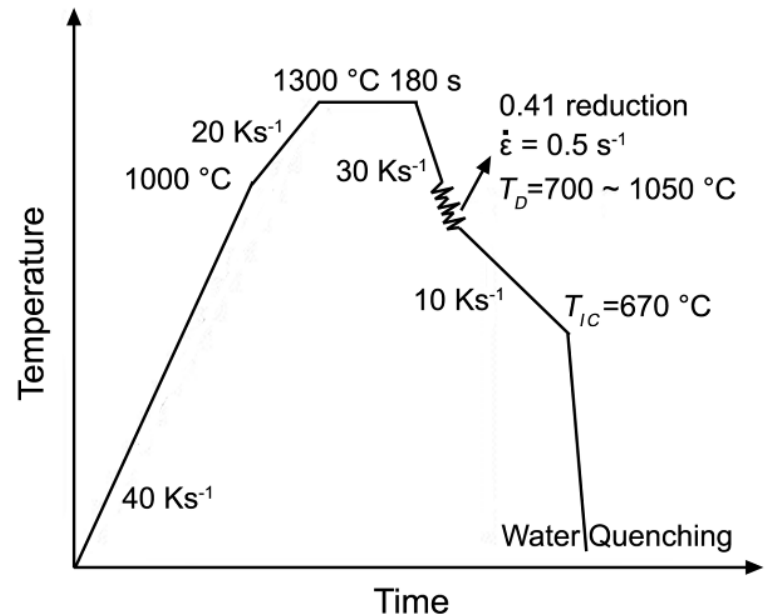

b

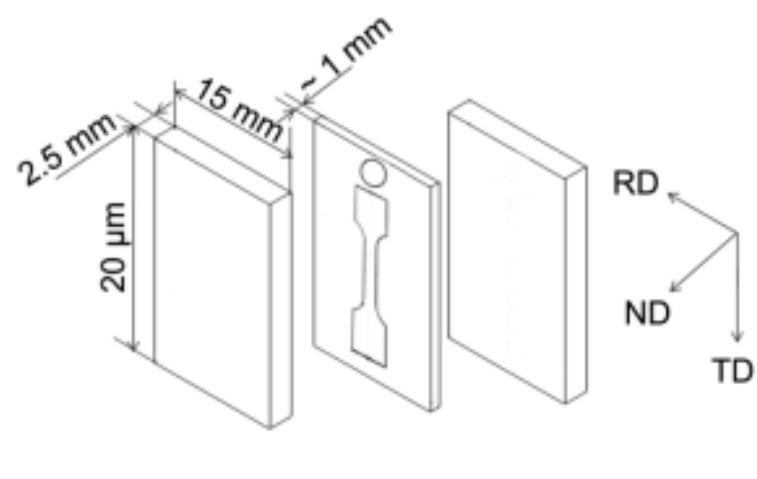

Figure 1. Schematic diagrams of (a) thermo-mechanical schedules and (b) sandwiched sample. The deformation axis is along normal direction. $R D$ is rolling direction, $N D$ is normal direction and $T D$ is transverse direction.

Since our thermo-mechanical processing simulates plain strain compression during hot rolling, the rolling convention (Fig. 1(b)) is used throughout the text such that the compression direction is parallel to the normal direction (ND) and the samples extended along the rolling direction (RD) and were constrained along the transverse direction (TD). For microstructure characterisation, the deformed samples were cut parallel to the RD-ND plane and the observations were carried out in the centre of the deformed area. After hot mounting and standard mechanical polishing, the samples were etched using 2 vol. \% nital. The centre of the cross section was investigated using a Leica DMR research optical microscope and a JEOL JSM-7001F field emission gun (FEG) - SEM. Area fractions of phases were calculated based on pixel counts of different grey scales using Image Pro-Plus and Photoshop software. The equivalent circle diameter (ECD) was calculated using at least 260 ferrite grains or second phase regions in optical micrographs. 
EBSD and TEM were conducted on selected samples, namely the DT 750, DT 800 and DT 850 samples. After polishing to the colloidal silica stage, EBSD was undertaken on the same JEOL JSM-7001F FEG - SEM, operating at $15 \mathrm{kV}$ accelerating voltage, $5.1 \mathrm{nA}$ probe current and a working distance of $12 \mathrm{~mm}$. A step size of $0.1 \mu \mathrm{m}$ was used to map an area of $180 \times$ $240 \mu \mathrm{m}^{2}$. The maps returned an overall indexing rate of $\sim 98 \%$ and were further processed using the Oxford Instruments Channel-5 software package. Any potential wild orientation spikes were first eliminated then cyclic extrapolation from 8 to 6 neighbours filled in zero solutions. In all maps, subgrain/grain structures were reconstructed using $2^{\circ}$ as the minimum misorientation angle and a minimum spatial resolution of 3 pixels was also maintained constant. Misorientation angles $(\theta)$ within the range $2^{\circ} \leq \theta<15^{\circ}$ are defined as low angle grain boundaries (LAGBs), whereas $\theta \geq 15^{\circ}$ denotes high angle grain boundaries (HAGBs). $\Sigma 3$ boundaries are defined using the $\langle 111\rangle 60^{\circ}$ axis-angle relationship via the Palumbo-Aust criterion (i.e., $\Delta \theta \leq 15^{\circ} \Sigma^{-5 / 6}$ with a tolerance limit $\Delta \theta=6^{\circ}$ ) [32]. Average grain size and subgrain size were determined via the equivalent circle diameter method using boundary identification angles of $15^{\circ}$ and $2^{\circ}$, respectively, and a fixed critical boundary completion angle of $2^{\circ}$.

Since the microstructures of the DT 750, DT 800 and DT 850 samples generally comprised polygonal ferrite, SIF and second phase regions (bainite and martensite), all of which display the body-centred cubic (bcc) crystal lattice, the following procedure was developed to segment the EBSD maps. Firstly, a mean angular deviation (MAD) criterion was applied to separate the second phase regions from the total ferrite fraction (comprising polygonal ferrite and SIF). MAD is the average angular misfit (in degrees) between detected and simulated Kikuchi bands and is a measure of the goodness of fit. Here the second phase regions exhibit higher MAD values due to the elastically distorted lattices and higher density of crystalline 
defects in bainite or martensite compared to ferrite. Consequently, a MAD threshold value of $0.15^{\circ}$ was used such that higher values correspond to the second phase regions. Secondly, a subgrain/grain size criterion was applied to separate the total ferrite fraction into polygonal ferrite and SIF. Here, and only for the purpose of segmenting the total ferrite fraction, the boundary identification angle was kept at $2^{\circ}$, while the critical subgrain boundary completion angle was reduced from $2^{\circ}$ to $0.5^{\circ}$. Reducing the boundary completion angle ensures full delineation of the individual subgrains of SIF. Then a subgrain size threshold of $4 \mu \mathrm{m}$ was used such that smaller values correspond to the SIF fraction.

Following phase segmentation, a Matlab code based on the MTex toolbox [33] was written to calculate the angular deviation from the ideal $\mathrm{K}-\mathrm{S}$ and $\mathrm{N}-\mathrm{W}$ ORs for each microstructure constituent in the DT 750 map. Firstly, the misorientation angles/axes were calculated between each two neighbouring grains (for polygonal ferrite and SIF) or martensitic/bainitic laths (in the second phase regions). Subsequently, the calculated misorientation angles/axes were compared with the inter-variant misorientation angles/axes of the 24 possible variants of the K-S OR [34] and the 12 possible variants of the $\mathrm{N}-\mathrm{W}$ OR [35]. The minimum angular deviation value out of the resultant set of solutions was assigned to the grain/lath under consideration. A more detailed description of this approach was given in Ref. [36].

In order to obtain more statistically representative texture information, an additional set of larger maps $\left(547 \times 602 \mu \mathrm{m}^{2}\right)$ were acquired on the DT 750, DT 800 and DT 850 samples using a step size of $0.5 \mu \mathrm{m}$. The orientation distribution functions (ODFs) $\left(\phi_{2}=0^{\circ}\right.$ and $45^{\circ}$ sections) of the small and large maps are depicted using Bunge's notation after exporting EBSD data to the JTex software [37]. 
For TEM analysis, $3 \mathrm{~mm}$ diameter discs were cut through ND direction (Fig. 1(b)) and then mechanically polished to $80 \mu \mathrm{m}$ thickness. After this, thin foils were prepared using twin-jet electropolishing with an electrolyte containing 10 vol.\% perchloric acid in methanol. Brightfield imaging and selected area electron diffraction were undertaken on a JEOL 2011 TEM operating at $200 \mathrm{kV}$.

Dog-bone tensile samples were cut from the RD-TD plane (Fig. 1(b)) with $4.9 \mathrm{~mm}$ gauge length (parallel to TD) and $2.1 \mathrm{~mm}$ width (parallel to RD). An in-house modified Kammrath and Weiss GmbH tensile stage was used to carry out the tensile tests at a constant speed of 2 $\mu \mathrm{ms}^{-1}$, which corresponds to an initial strain rate of $4 \times 10^{-4} \mathrm{~s}^{-1}$. At least, two samples were tested for each condition.

\section{Results}

\subsection{The effect of deformation temperature on microstructure evolution}

a

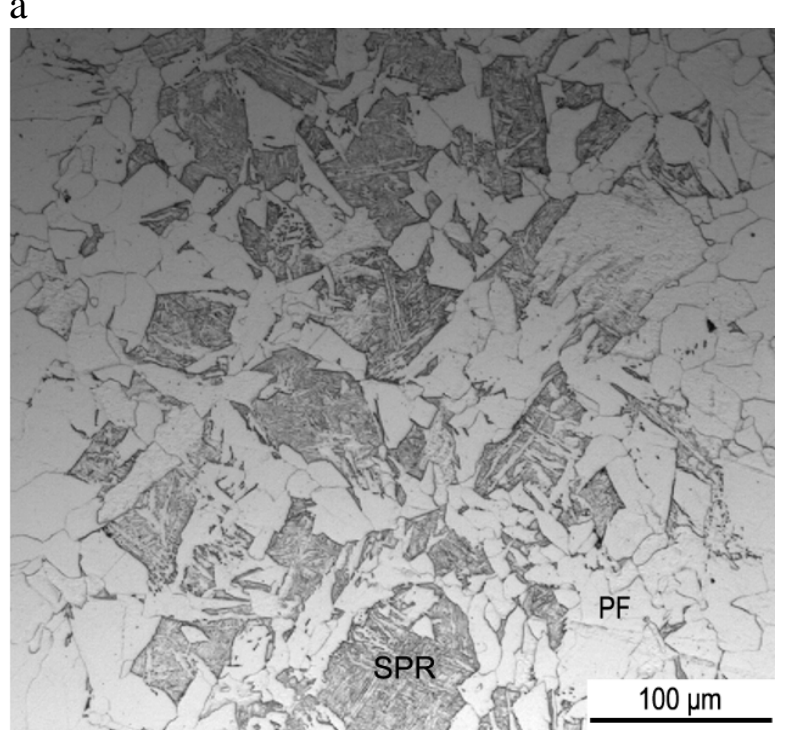

C b

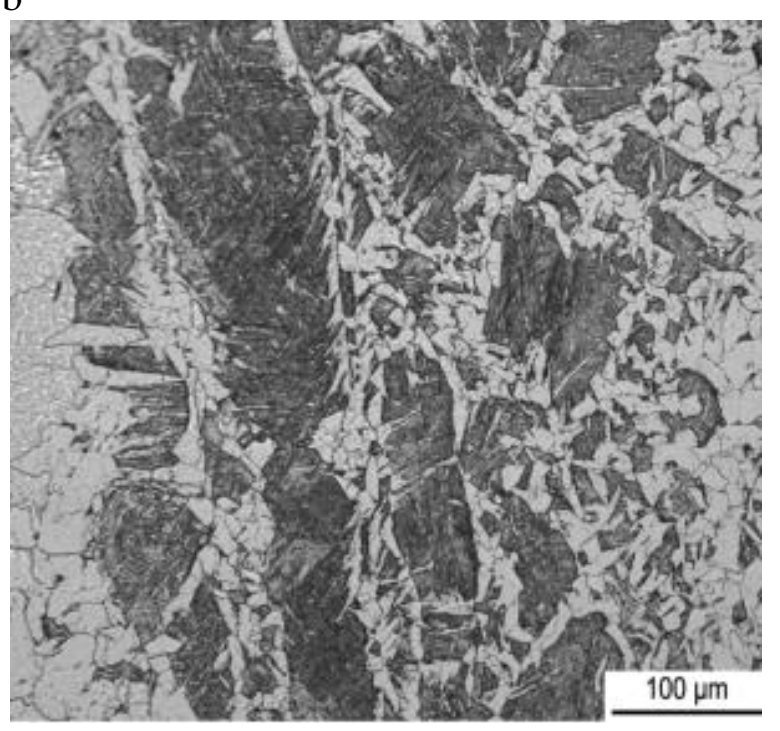

d 

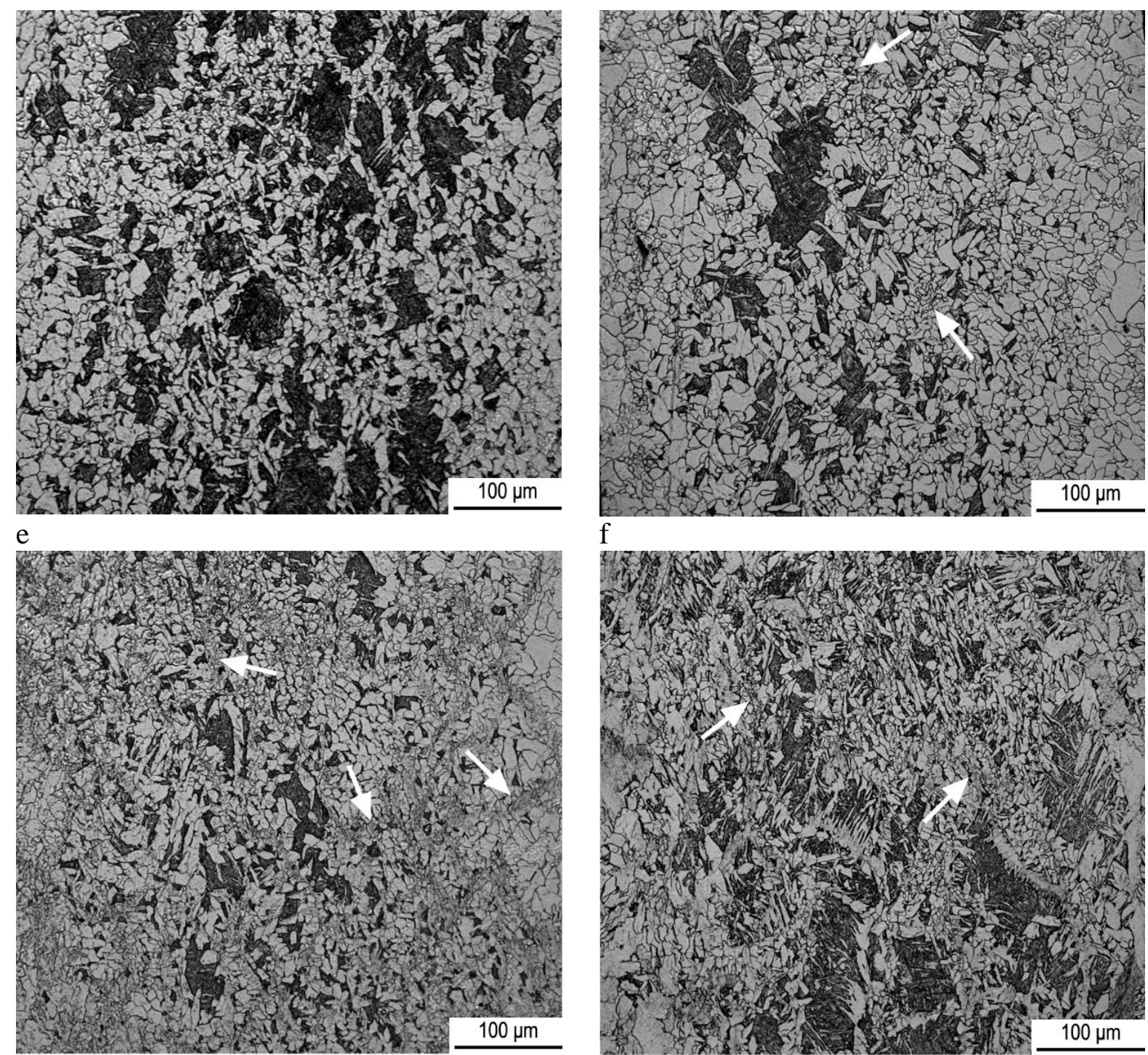

Figure 2. Optical images of (a) DT 1050, (b) DT 950, (c) DT 850, (d) DT 800, (e) DT 750 and (f) DT 700 samples. The ND and RD directions are respectively horizontal and vertical. $P F$ is polygonal ferrite, $S P R$ is second phase region.

Optical and scanning electron micrographs after deformation at different temperatures are shown in Figs. 2 and 3, respectively. After deformation at $1050{ }^{\circ} \mathrm{C}$ (DT 1050 sample), both ferrite and the second phase regions generally exhibited a polygonal shape. The second phase regions consisted of martensite and bainite (Fig. 3 (a)). For deformation temperatures below $1050{ }^{\circ} \mathrm{C}$, the second phase regions became elongated. A higher ferrite fraction was observed in the near-surface regions compared to the centre of the samples (Fig. 2) probably due to the through-thickness strain gradient [6]. After deformation at $950{ }^{\circ} \mathrm{C}$ (DT 950 sample), some interspersed ferrite (Fig. 3(b)) was observed inside second phase regions. Deformation at 800, 
750 and $700{ }^{\circ} \mathrm{C}$ resulted in some patches indicated by arrows in Figs. 2 (d, e, f), which were identified to be SIF grains. This is more clearly demonstrated in Figs. 3(d, e, f, g). After deformation at $800^{\circ} \mathrm{C}$ (DT 800 sample), only a small fraction of SIF $(0.04 \pm 0.01$, as estimated from optical micrographs) was observed (Fig. 3(d)). With a decrease in the deformation temperature to $750{ }^{\circ} \mathrm{C}$ (DT 750 sample), the fraction of SIF increased significantly to $0.18 \pm 0.03$. With further decrease in the deformation temperature to $700{ }^{\circ} \mathrm{C}$ (DT 700 sample), the fraction of SIF decreased to $0.03 \pm 0.01$. Some Widmänstatten ferrite was also observed at $700{ }^{\circ} \mathrm{C}$ as indicated by the arrow in Fig. 3(h).

a

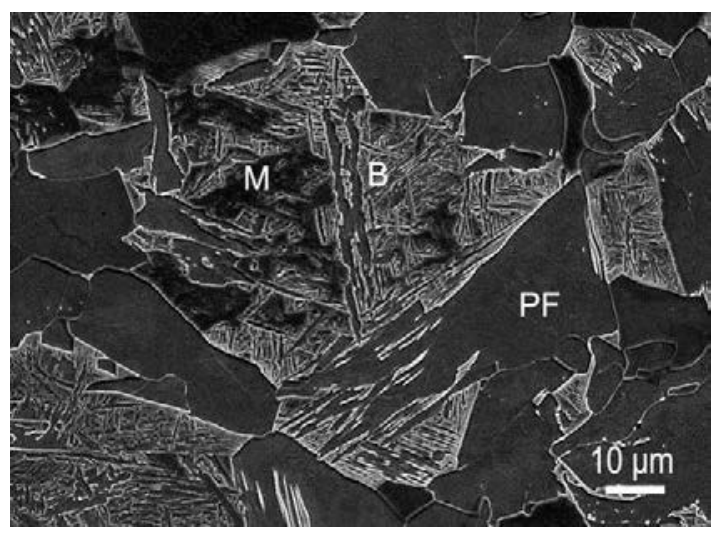

C



e b

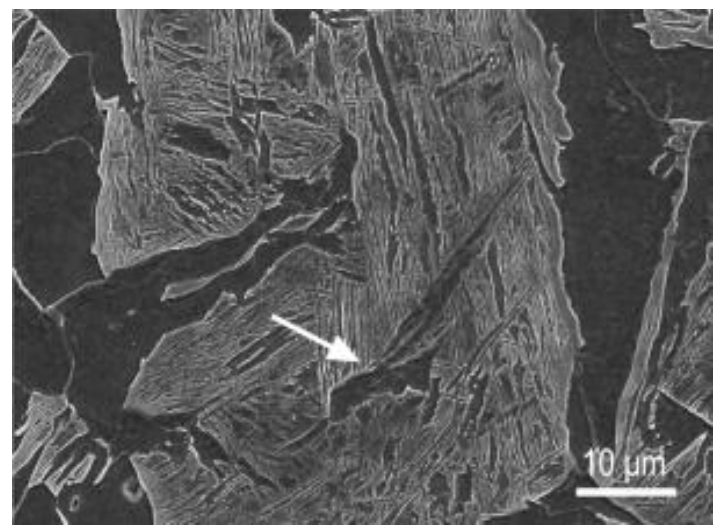

d



f 


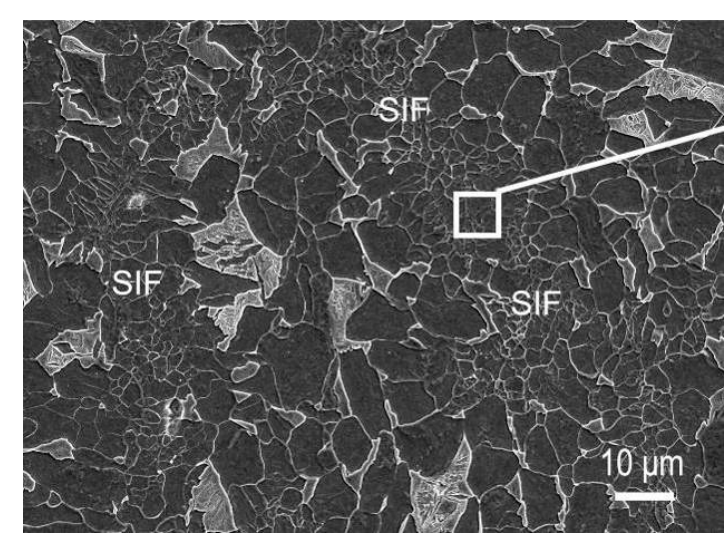

g

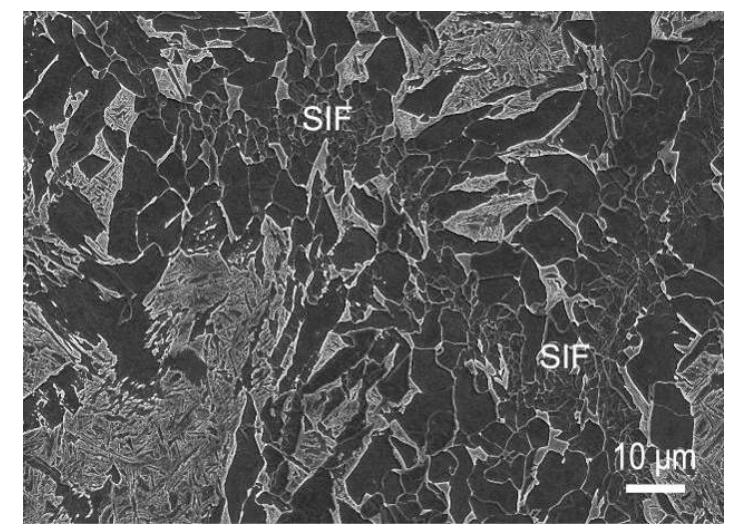

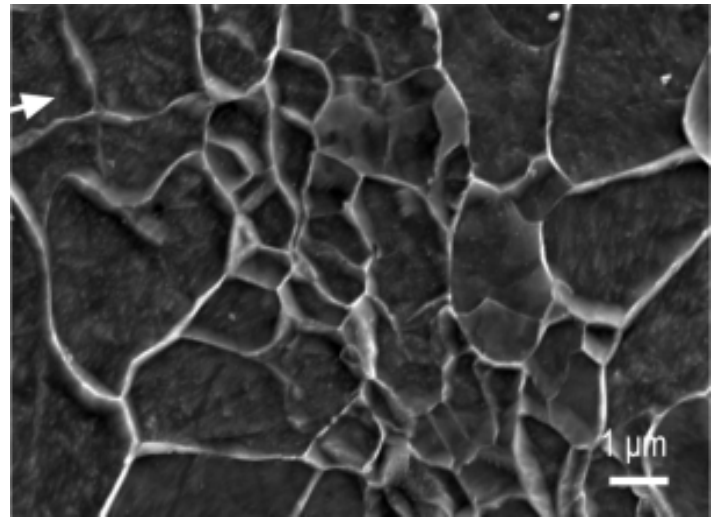

$\mathrm{h}$

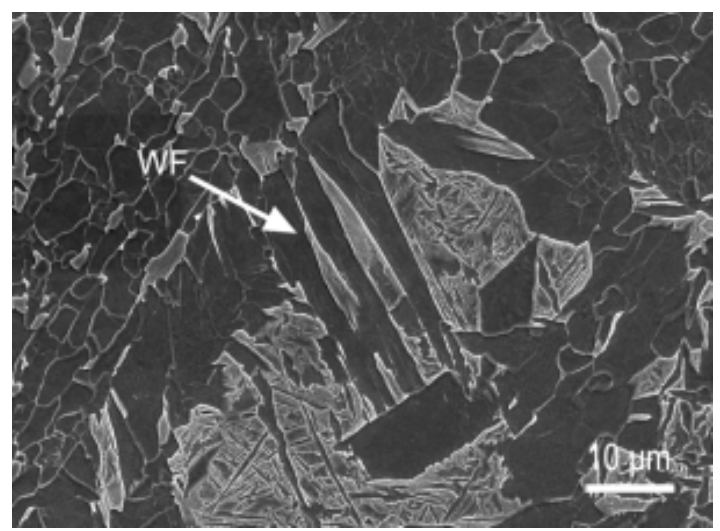

Figure 3. Selected SEM images of (a) DT 1050, (b) DT 950, (c) DT 850, (d) DT 800, (e, f) DT 750, and (g, h) DT 700 samples. $P F$ is polygonal ferrite, $B$ is bainite, $M$ is martensite, SIF is strain-induced ferrite and $W F$ is Widmänstatten ferrite.

As seen from Table 1 and Fig. 4 (a), when deformation temperature decreased from 1050 to $950{ }^{\circ} \mathrm{C}$, the ferrite fraction decreased from 0.63 to 0.53 . With a further decrease in the deformation temperature to $750{ }^{\circ} \mathrm{C}$, the ferrite fraction increased to a maximum of 0.81 , which subsequently decreased to 0.7 after deformation at $700{ }^{\circ} \mathrm{C}$. The average ferrite grain size showed a maximum of $11.9 \pm 7.7 \mu \mathrm{m}$ at $950{ }^{\circ} \mathrm{C}$ and a minimum of $3.1 \pm 2.3 \mu \mathrm{m}$ at $750{ }^{\circ} \mathrm{C}$ (Fig. 4(b)). The average grain size of SIF exhibited a similar trend to polygonal ferrite with a minimum of $2.1 \pm 0.9 \mu \mathrm{m}$ after deformation at $750{ }^{\circ} \mathrm{C}$ (Table 1 ). The average size of second phase region decreased from $20.0 \pm 18.0$ to $5.5 \pm 4.3 \mu \mathrm{m}$ when the deformation temperature decreased from 1050 to $750{ }^{\circ} \mathrm{C}$ (Fig. 4(b) and Table 1). Then the average second phase region size increased to $6.6 \pm 8.2 \mu \mathrm{m}$ with a decrease in deformation temperature to $700{ }^{\circ} \mathrm{C}$. In 
addition, the largest size of the ferrite and second phase region declined from 66 to $26 \mu \mathrm{m}$ and 179 to $44 \mu \mathrm{m}$, respectively, with a decrease in deformation temperature from 1050 to $750{ }^{\circ} \mathrm{C}$. This indicates that the microstructure tends to become more uniform with decreasing deformation temperature. However, a further decrease in the deformation temperature to $700{ }^{\circ} \mathrm{C}$ led to a significant increase in the maximum sizes of ferrite and second phase regions due to a decrease in polygonal ferrite fraction.



C b

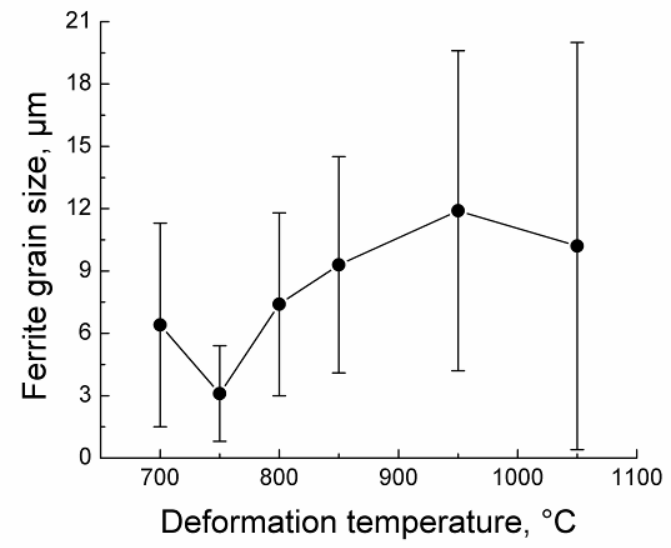



Figure 4. The dependences of (a) ferrite fraction, (b) ferrite grain size and (c) the size of second phase region on deformation temperature. 
Table 1. Summary of microstructure statistics.

\begin{tabular}{cccccccc}
\hline & \multirow{2}{*}{$\begin{array}{c}\text { Ferrite } \\
\text { fraction }\end{array}$} & Ferrite & $\begin{array}{c}\text { Second phase } \\
\text { region }\end{array}$ & Ferrite & $\begin{array}{c}\text { Second phase } \\
\text { region }\end{array}$ & $\begin{array}{c}\text { Polygonal } \\
\text { ferrite }\end{array}$ & $\begin{array}{c}\text { Strain-induced } \\
\text { ferrite }\end{array}$ \\
\cline { 3 - 7 } & & & 66 & 74 & -- & -- \\
DT 1050 & $0.63 \pm 0.01$ & $10.2 \pm 9.8$ & $20.0 \pm 18.0$ & 66 & 179 & -- & -- \\
DT 950 & $0.53 \pm 0.02$ & $11.9 \pm 7.7$ & $13.0 \pm 18.8$ & 58 & 109 & -- & -- \\
DT 850 & $0.66 \pm 0.01$ & $9.3 \pm 5.2$ & $12.0 \pm 13.3$ & 37 & 87 & $8.9 \pm 4.1$ & $2.9 \pm 0.7$ \\
DT 800 & $0.78 \pm 0.01$ & $7.4 \pm 4.4$ & $7.8 \pm 8.0$ & 37 & 44 & $6.5 \pm 2.7$ & $2.1 \pm 0.9$ \\
DT 750 & $0.81 \pm 0.02$ & $3.1 \pm 2.3$ & $5.5 \pm 4.3$ & 26 & 88 & $8.5 \pm 5.0$ & $2.8 \pm 0.7$ \\
DT 700 & $0.70 \pm 0.02$ & $6.4 \pm 4.9$ & $6.6 \pm 8.2$ & 50 & & \\
\hline
\end{tabular}

\subsection{Microstructure characterisation using transmission electron microscopy}

As seen in the above optical and scanning electron microscopy results, SIF formation occurred following deformation in the temperature range $800-700{ }^{\circ} \mathrm{C}$ (DT 800, DT 750 and DT 700 samples). Therefore, further microstructure characterisation was undertaken on the DT 800 and DT 750 samples using TEM and EBSD. The DT 850 sample was also investigated for comparison. Due to the detrimental effect of Widmänstatten ferrite (observed after deformation at $700{ }^{\circ} \mathrm{C}$ in Fig. 3(h)) on the final mechanical properties, the DT 700 sample was not considered for further analysis.

Typical polygonal ferrite grains in DT 850 and DT 750 samples are shown in Figs. 5(a, b) and Figs. 6(a, b), respectively. The dislocation substructures in polygonal ferrite comprised isolated dislocations (Fig. 5(a)), dislocation tangles (Figs. 5(b) and 6(a)) and areas of increased dislocation density adjacent to the interfaces between polygonal ferrite and second phase regions (Fig. 6(b)), resulting from the increased local strains due to the volume change associated with the accommodation of martensitic and/or bainitic transformations. The dislocation structures in SIF did not show significant variation from that in the polygonal ferrite. However, a slightly higher average dislocation density was observed in the SIF $\left(5.1 \pm 0.5 \times 10^{13} \mathrm{~m}^{-2}\right)$ compared to polygonal ferrite $\left(4.6 \pm 0.4 \times 10^{13} \mathrm{~m}^{-2}\right)$ in the DT 750 sample 
due to the preferential nucleation of SIF along prior austenite grain boundaries where more deformation defects existed. Well-arranged dislocation walls in the polygonal ferrite (Figs. 5(b) and 6(d)) and SIF (Fig. 6(c)) suggest that recovery could be taking place during cooling to $670{ }^{\circ} \mathrm{C}$ (prior to quenching).
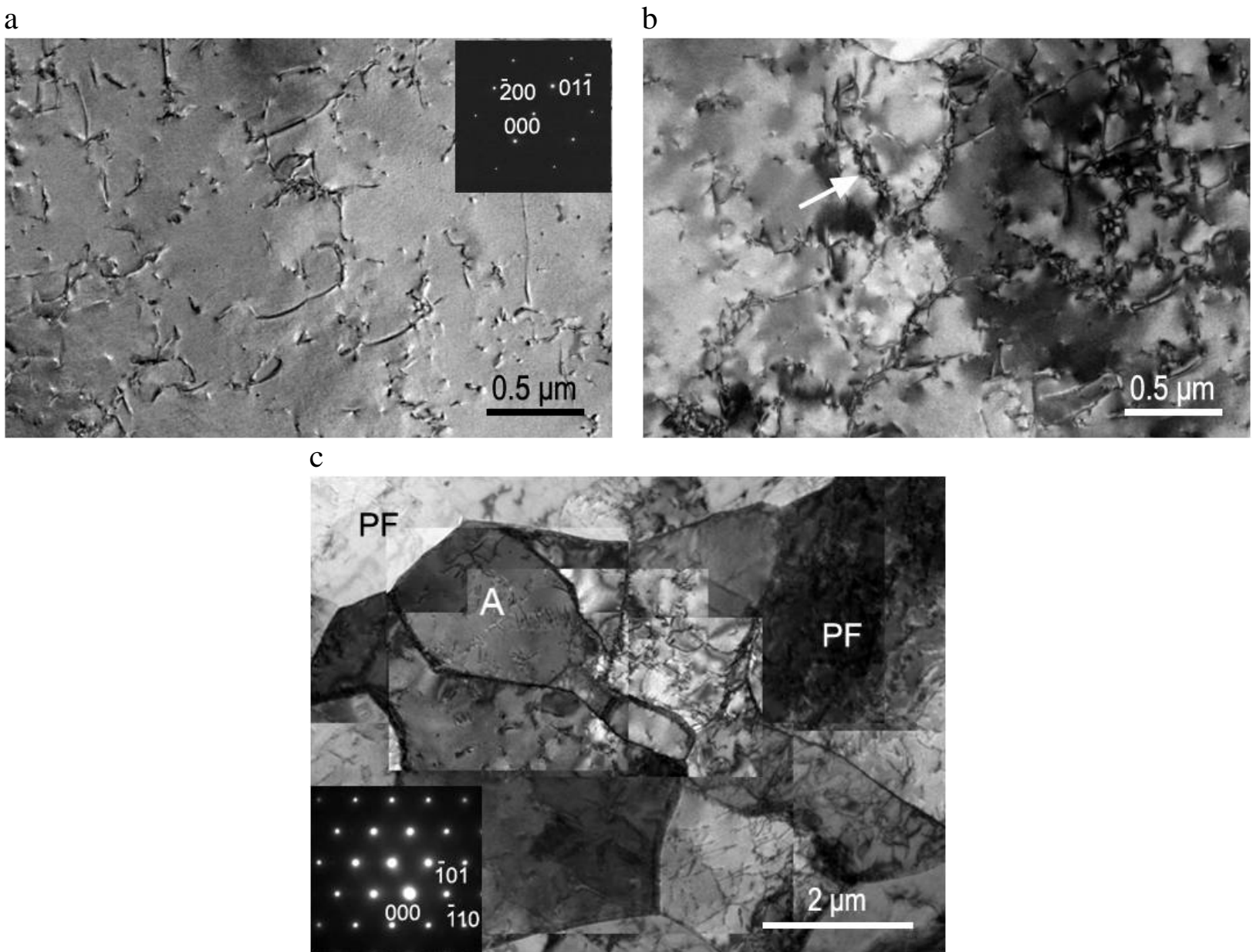

Figure 5. TEM images of (a, b) polygonal ferrite in DT 850 sample (the zone axis of inset is [011] $]_{\alpha}$ ) and (c) straininduced ferrite in DT 800 sample (the zone axis of diffraction pattern from A shown in inset is [111] $]_{\alpha}$ ). $P F$ is polygonal ferrite. The arrow in (b) shows dislocation walls in polygonal ferrite. 
a

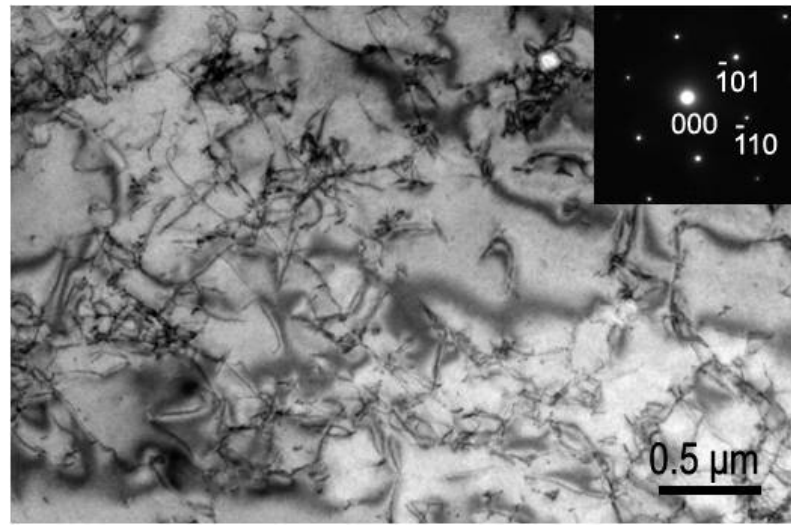

b

C

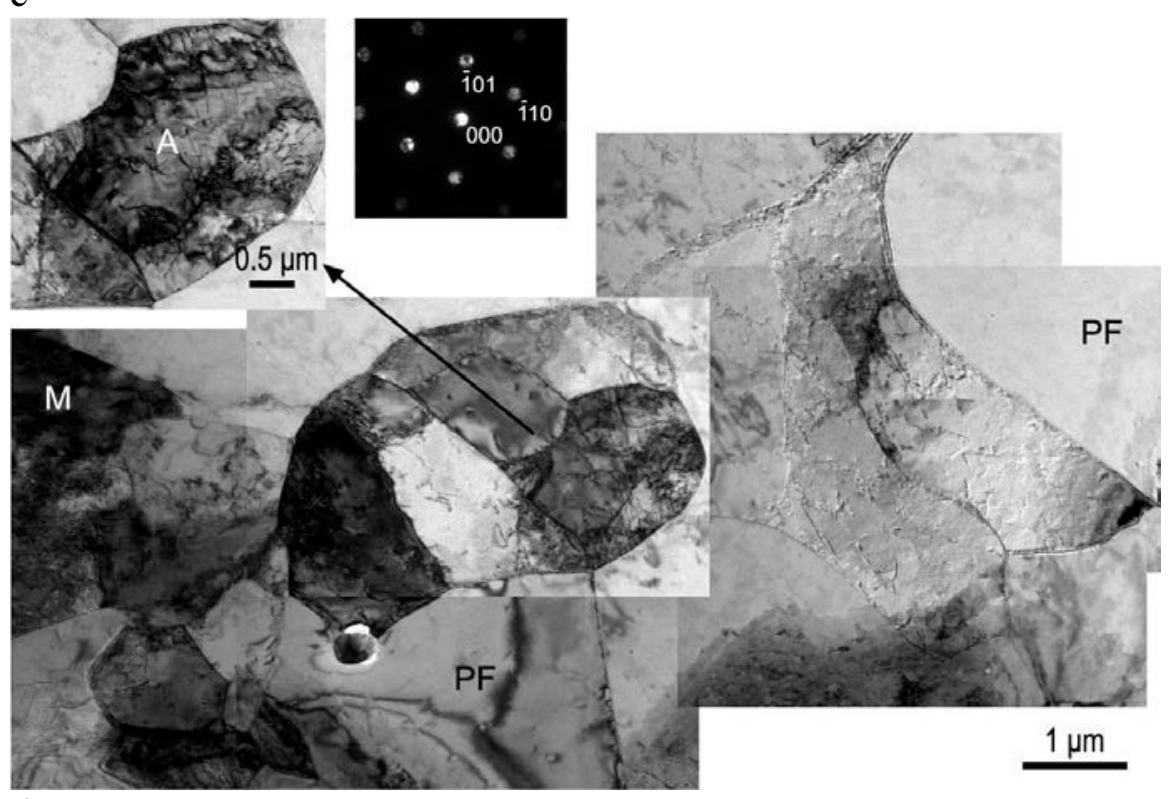

$\mathrm{d}$

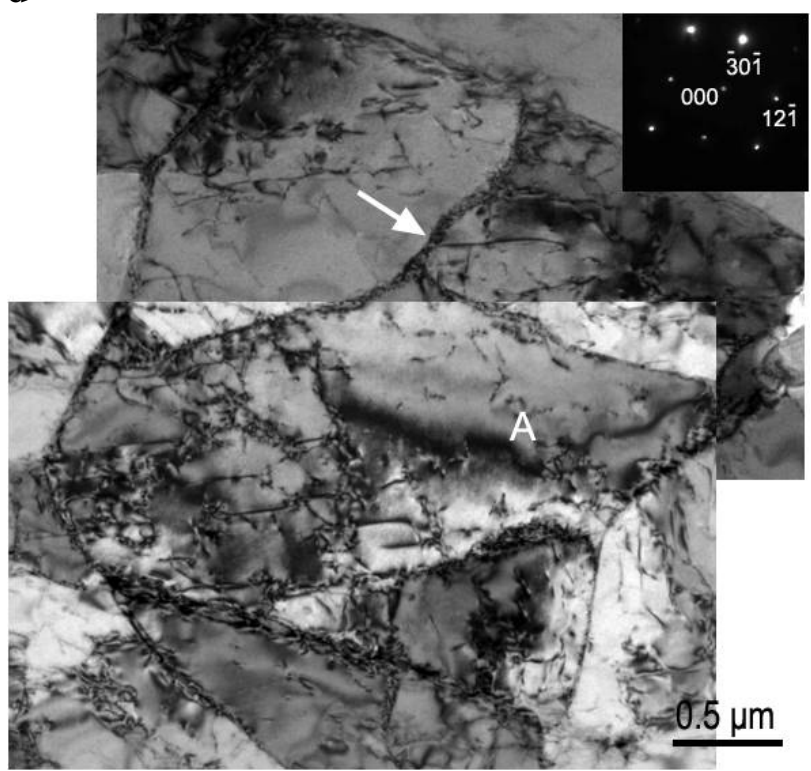

Figure 6. TEM images of DT 750 sample: (a, b) typical polygonal ferrite microstructure after deformation (the zone axis of inset in (a) is [111 $]_{\alpha}$ ); (c) strain-induced ferrite (the zone axis of diffraction pattern from A shown in inset is [111] $]_{\alpha}$ ); (d) dislocation walls indicated by the white arrow in polygonal ferrite (the zone axis of diffraction pattern from A shown in inset is $\left.[\overline{1} 23]_{\alpha}\right)$. $P F$ is polygonal ferrite and $M$ is martensite. 


\subsection{Electron backscattering diffraction characterisation of microstructure constituents}

The band contrast maps in Figs. 7(a, c, e) show the variation in grayscale contrast between ferrite (polygonal ferrite and SIF) and the second phase regions. The lath-like structures of the second phase regions contained a relatively high fraction of $\Sigma 3\left(60^{\circ}\langle 111\rangle\right)$ boundaries, typically arising from the self-accommodation of transformation strain during austenite-tobainite/martensite transformation with the operation of the $\mathrm{K}-\mathrm{S}$ [34] or $\mathrm{N}-\mathrm{W}$ [35] ORs. The results of microstructure segmentation are superimposed on band contrast maps in Figs.7(b, d, f), with polygonal ferrite, SIF and second phase regions shown in blue, green and red, respectively. With a decrease in deformation temperature from 850 to $750{ }^{\circ} \mathrm{C}$, the SIF fraction increased from 0 to 0.18 , and the second phase fraction decreased from 0.32 to 0.14 (which corresponds to the data obtained using optical microscopy (Table 1)). The SIF average grain size and subgrain size determined using EBSD were respectively $2.6 \pm 1.0$ and $1.8 \pm 0.8 \mu \mathrm{m}$ (DT 750 sample), and $2.5 \pm 0.5$ and $2.1 \pm 0.5 \mu \mathrm{m}$ (DT 800 sample). These values are again similar to the SIF average grain sizes $(2-3 \mu \mathrm{m})$ measured using optical images (Table 1).

a

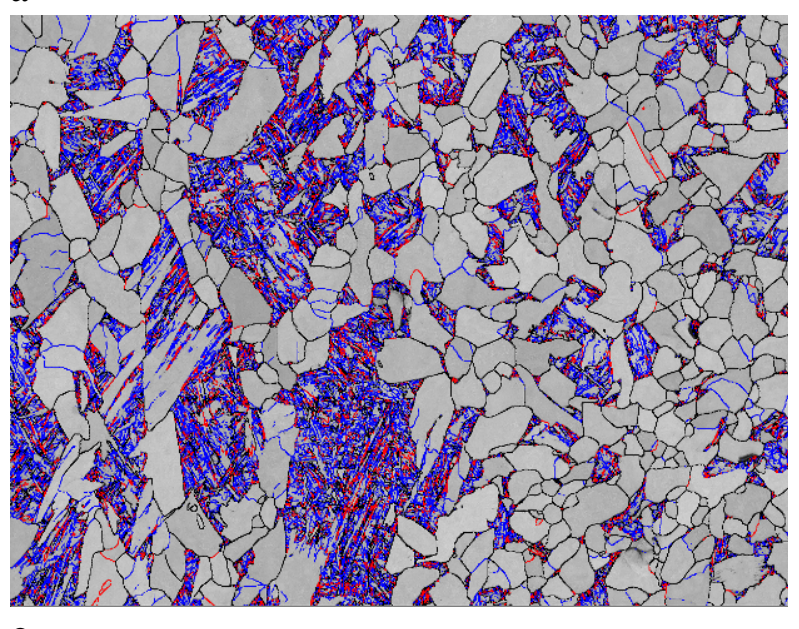

C b

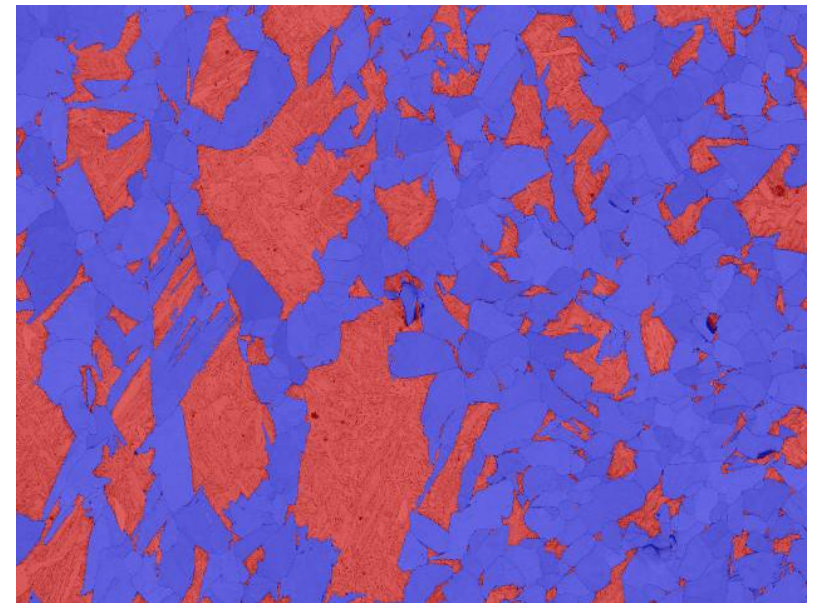

d 

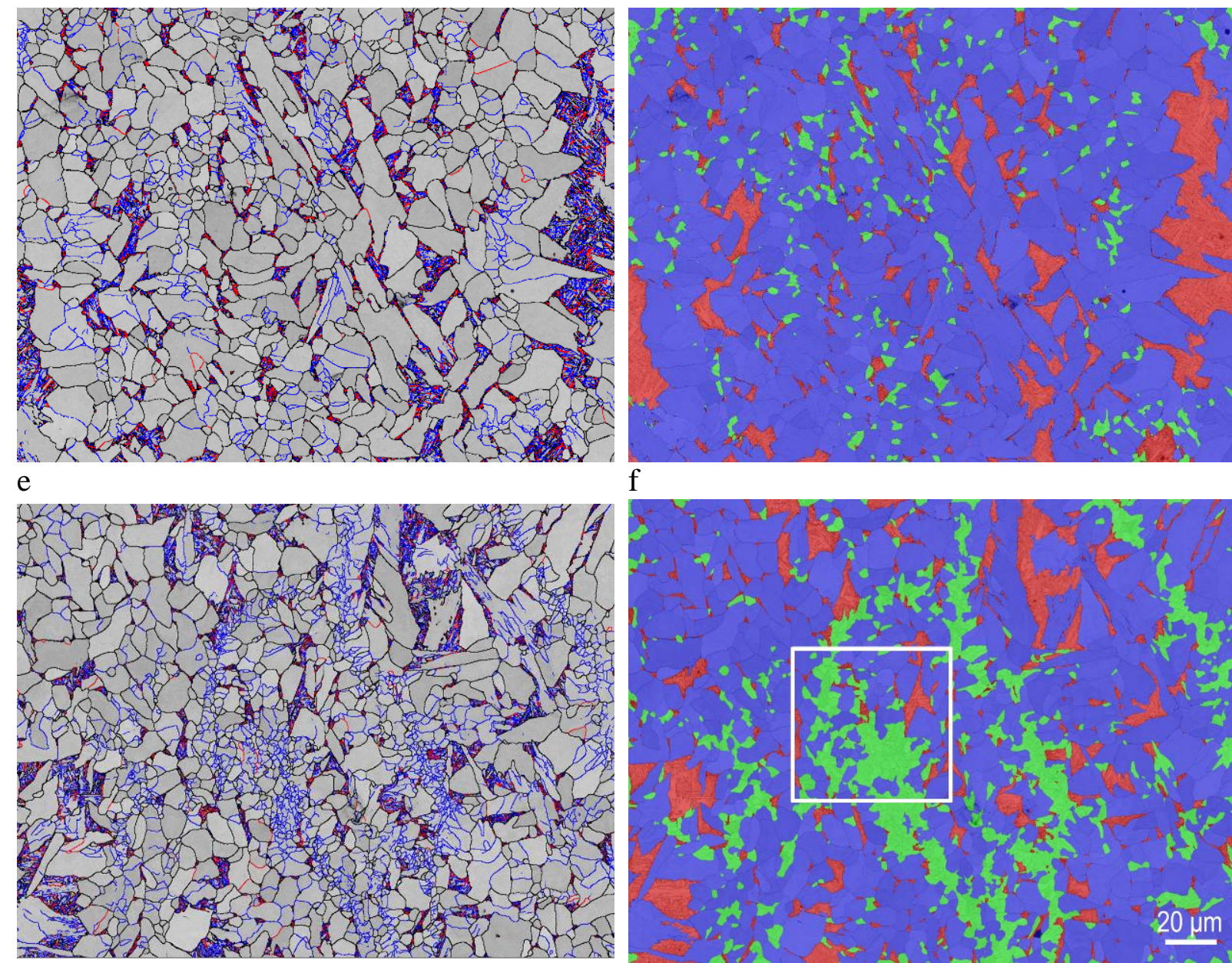

Figure 7. (a, c, e) EBSD maps of band contrast with grain boundaries (LAGBs $=2-15^{\circ}=$ blue, $\mathrm{HAGBs} \geq 15^{\circ}=$ black and $\langle 111\rangle 60^{\circ} \Sigma 3=$ red) and $(b, d, f)$ phase separation maps for $(a, b)$ DT 850, (c, d) DT 800 and (e, f) DT 750 samples, respectively. The ND and RD directions are respectively horizontal and vertical. Second phase regions are red, polygonal ferrite is blue and strain-induced ferrite is green.

Fig. 8 shows the misorientation angle distributions in different microstructure constituents, and the corresponding fractions of LAGBs are listed in Table 2. As can be seen, the misorientation angle distributions for the full maps (including all phases) of the three investigated temperatures generally exhibit similar trends, with LAGB fractions within the range of $0.37-0.45$. Here one may argue that the high LAGB fraction in the total ferrite subset (comprising polygonal ferrite and SIF, Fig. 8(c)) could simply be forming due to deformation and subsequent recovery of polygonal ferrite. However, since the deformation temperature of $750{ }^{\circ} \mathrm{C}$ is much higher than the $A r_{3}$ temperature $\left(695{ }^{\circ} \mathrm{C}\right)$, it is SIF that is expected to form during deformation, whereas polygonal ferrite forms later on during cooling. 
In other words, there are no deformation substructures in polygonal ferrite to be recovered during cooling. It follows that the observed high fraction of LAGBs is mainly associated with SIF formation (Fig. 8(c))) as further discussed in section 4.1. The observed increase in the LAGBs fraction in both polygonal ferrite and SIF with decreasing deformation temperature is likely due to a decrease in the recovery rate (see for example Figs. 6(c, d)) during cooling to $670{ }^{\circ} \mathrm{C}$.

a



C b

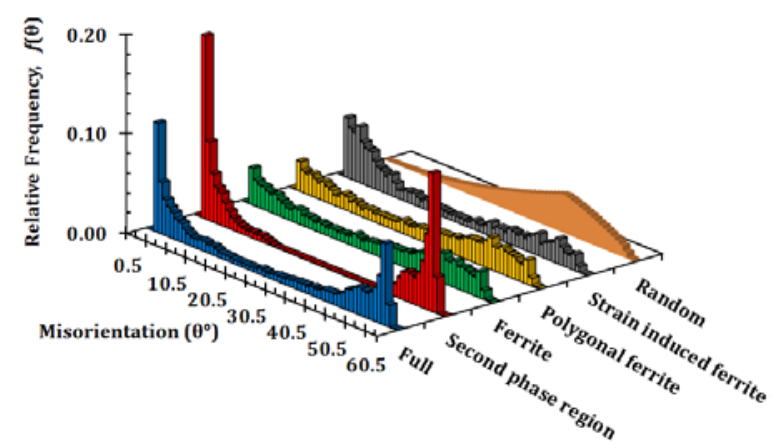

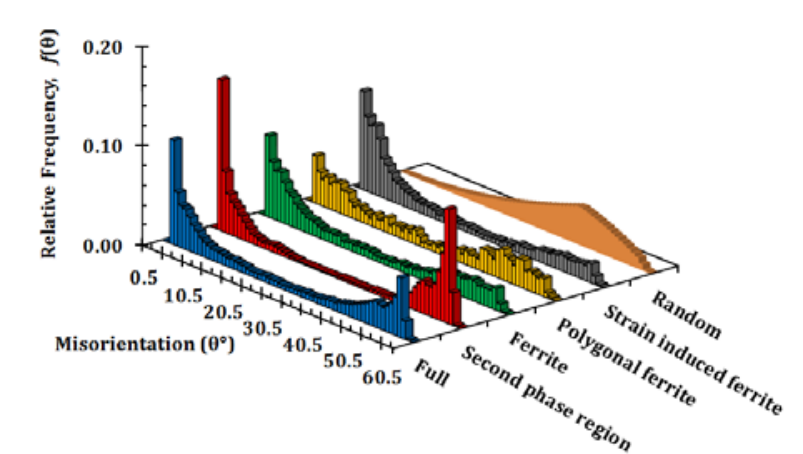

Figure 8. Misorientation angle distributions in (a) DT 850, (b) DT 800 and (c) DT 750 samples. Random denotes the McKenzie distribution for untextured cubic materials.

Table 2. Fractions of low angle grain boundaries $\left(2-15^{\circ}\right)$ after deformation at different temperatures.

\begin{tabular}{cccccc}
\hline & Full map & Second phase region & Ferrite & Polygonal ferrite & Strain-induced ferrite \\
\hline DT 750 & 0.42 & 0.42 & 0.46 & 0.34 & 0.57 \\
DT 800 & 0.37 & 0.48 & 0.25 & 0.24 & 0.47 \\
DT 850 & 0.45 & 0.53 & 0.24 & 0.24 & N/A \\
\hline
\end{tabular}


The misorientation distributions of the second phase regions in all three conditions are typical of diffusionless transformation from austenite to bainite/martensite following the $\mathrm{K}-\mathrm{S}$ or $\mathrm{N}-$ W ORs, with misorientation angles between crystallographic variants being predominant in the ranges from 10.5 to $14.9^{\circ}$ and from 49.5 to $60.0^{\circ}[34,35]$. The observation of high fraction of low misorientation angles $\left(<10^{\circ}\right)$ in the second phase regions is also typical of fast diffusionless transformation [38]. Expectedly, the above misorientation peaks (associated with crystallographic variants) were not observed in the polygonal ferrite fraction which forms via diffusional transformation. Interestingly, these peaks were also absent from the misorientation distributions of SIF and it alludes to the diffusional mechanism of its formation.

\subsection{Texture evolution}

Fig. 9(a) is a schematic $\phi_{2}=0^{\circ}$ and $\phi_{2}=45^{\circ}$ ODF sections for rolled bcc steels, which identify the $\alpha$-fibre $(\langle 110\rangle|| \mathrm{RD})$ and $\gamma$-fibre $(\langle 111\rangle \| \mathrm{ND})$, along with the (001)[ $\overline{1} \overline{1} 0]$ rotated cube component. The orientations belonging to the bcc $\alpha$-fibre extend from (001)[1 $\overline{1} 0]$ through (112)[1 $\overline{1} 0]$ to (111)[1 $1 \overline{1} 0]$ in the range from $\Phi=0-55^{\circ}$ at $\phi_{1}=0^{\circ}$ and $\phi_{2}=45^{\circ}$. Orientations belonging to the $\gamma$-fibre includes two pairs of equivalent orientations (111)[1 $\overline{1} 0]$, (111)[0 $\overline{1} 1]$ and (111)[121], (111)[1 $\overline{1} 12]$; located between $\phi_{1}=60-90^{\circ}$ at $\Phi=54.5^{\circ}$ and $\phi_{2}=$ $45^{\circ}$. 

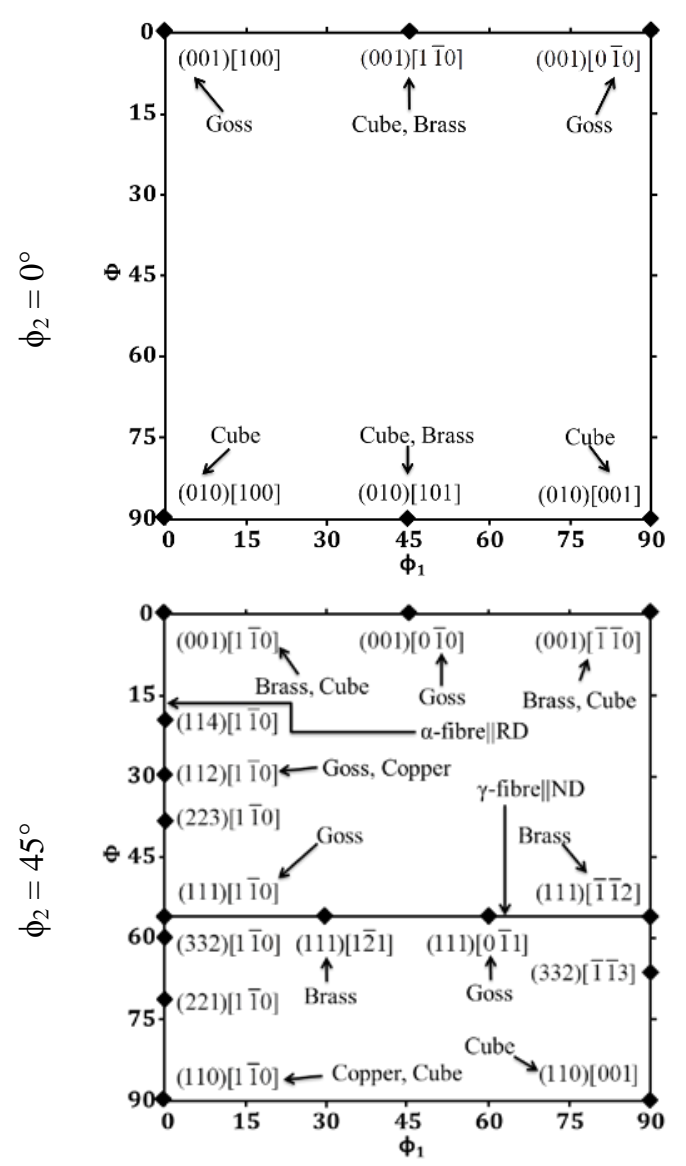

b
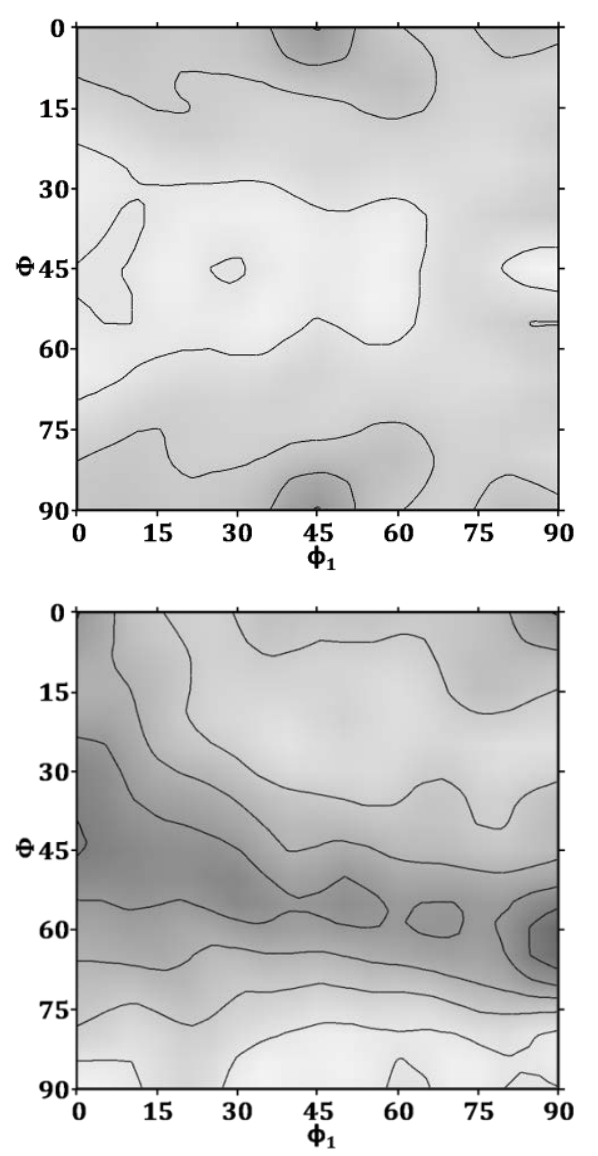

C
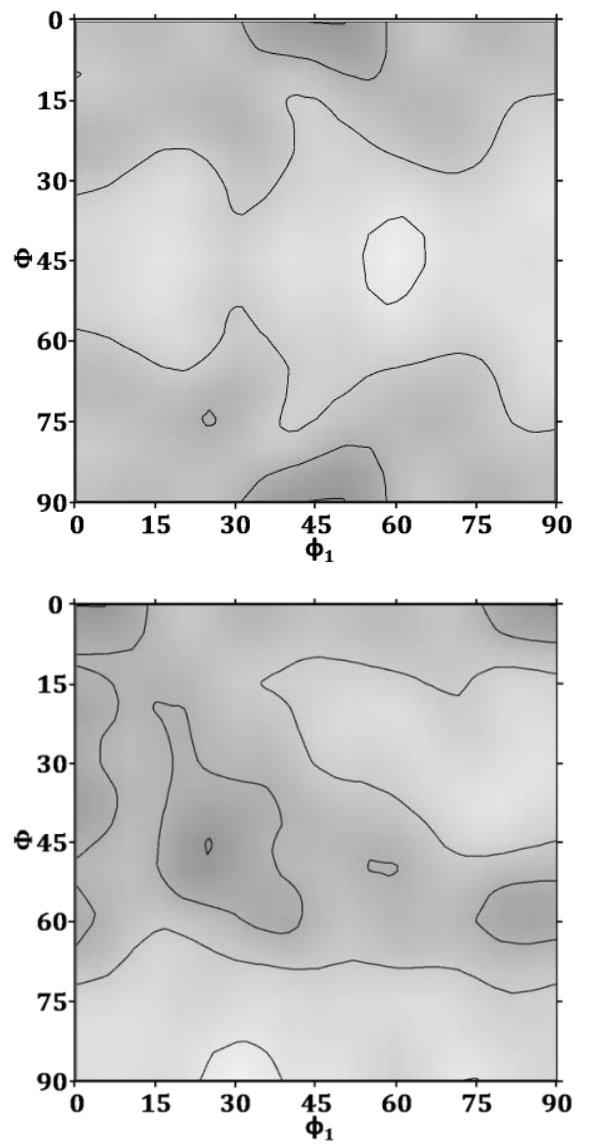

d
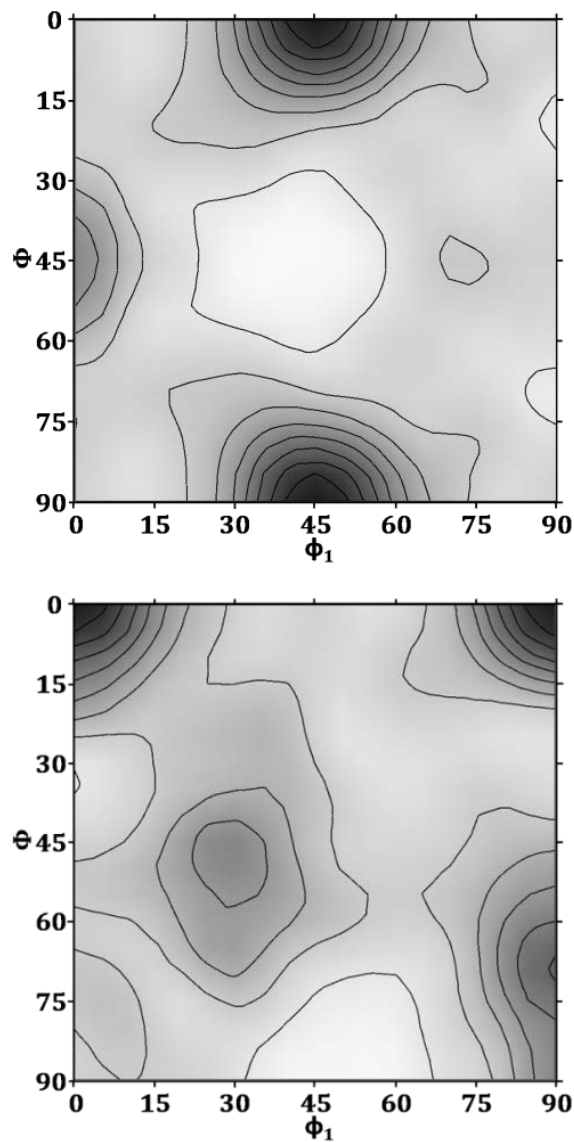

Figure 9. $\phi_{2}=0^{\circ}$ and $45^{\circ}$ ODF sections of the (a) ideal body-centred cubic product orientations with their major parent orientations named, (b) DT 850 , (c) DT 800 and (d) DT 750 samples from a scanning area of $547 \times 602 \mu \mathrm{m}^{2}$. 
When hot deformation of steel is undertaken in the austenite region, the crystallographic orientations of the parent face-centred cubic (fcc) austenite phase will affect the ones of the bcc transformation products (such as ferrite, bainite and/or martensite). Since the three investigated temperatures (850, 800 and $750{ }^{\circ} \mathrm{C}$ ) are below $T_{n r}$, austenite is expected to develop the $\beta$-fibre (extending from the Copper $(\mathrm{Cu},\{112\}\langle 111\rangle)$ to the Brass $(\mathrm{Br}$, $\{110\}\langle 112\rangle)$ through the $S(\{123\}\langle 634\rangle))$, along with a weaker Goss $(G,\{110\}\langle 001\rangle)$ component $[15,39,40]$. The transformation of the former parent fcc orientations to their bcc product orientations, following the K-S OR, is indicated in Fig. 9(a) [39]. The ODFs calculated from the large area $\left(547 \times 602 \mu \mathrm{m}^{2}\right)$ maps are shown in Figs. 9(b, c, d). The texture observed after deformation at $850{ }^{\circ} \mathrm{C}$ (DT 850 sample, Fig. 9(b)) exhibit a slightly curved $\gamma$ fibre skeleton line, typical of hot rolling textures in steel $[40,41]$. The orientations along this $\gamma$-fibre predominantly originate from the $\mathrm{Br}$ and $\mathrm{G}$ orientations in austenite. Similar texture was observed after deformation at $800{ }^{\circ} \mathrm{C}$ (DT 800 sample, Fig. 9(c)), with a slight decrease in intensity due to the smaller fraction of second phase regions [41]. After deformation at $750{ }^{\circ} \mathrm{C}$ (DT 750 sample, Fig. 9(d)), the $\gamma$-fibre became less uniform, with orientations clustering near (111)[1리 $]$ and (332)[ $\overline{1} \overline{1} 3]$, along with intensification of the rotated cube ((001) $[\overline{1} \overline{1} 0])$ orientation. This intense rotated cube orientation indicates the formation of a strong $\mathrm{Br}$ component in the pancaked austenite with decreasing deformation temperature [15, 41].

Fig. 10 depicts the ODFs (full map and the individual microstructure constituents) calculated from the DT 750 sample map shown in Fig. 7(f). It is noted that the ODF calculated from the full map (Fig. 10(a)) is generally in good agreement with the ODF calculated from the large area map shown before in Fig. 9(d). The lower intensity around the (001)[ $\overline{1} \overline{1} 0]$ rotated cube component in Fig. 10(a) is associated with the smaller investigated area. 
a
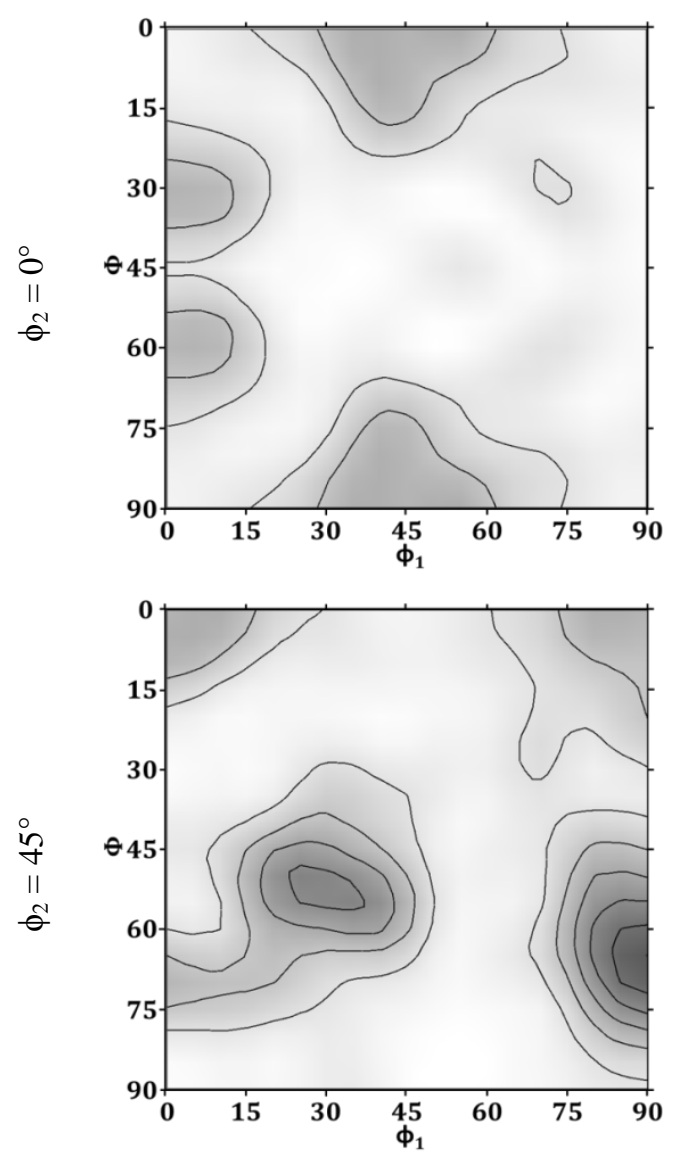

b
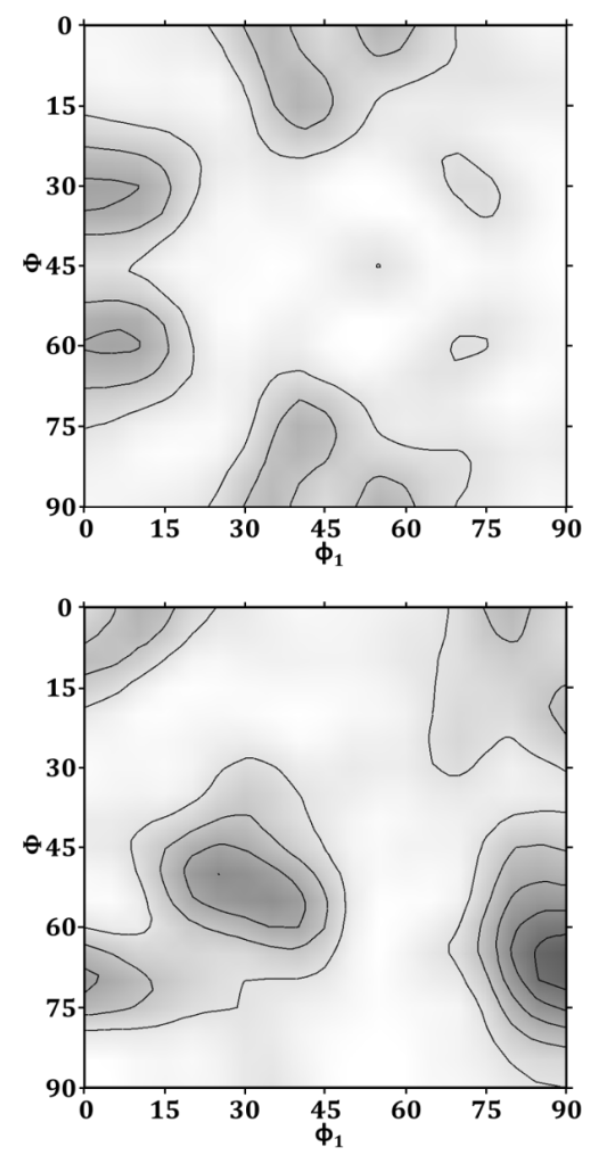

C
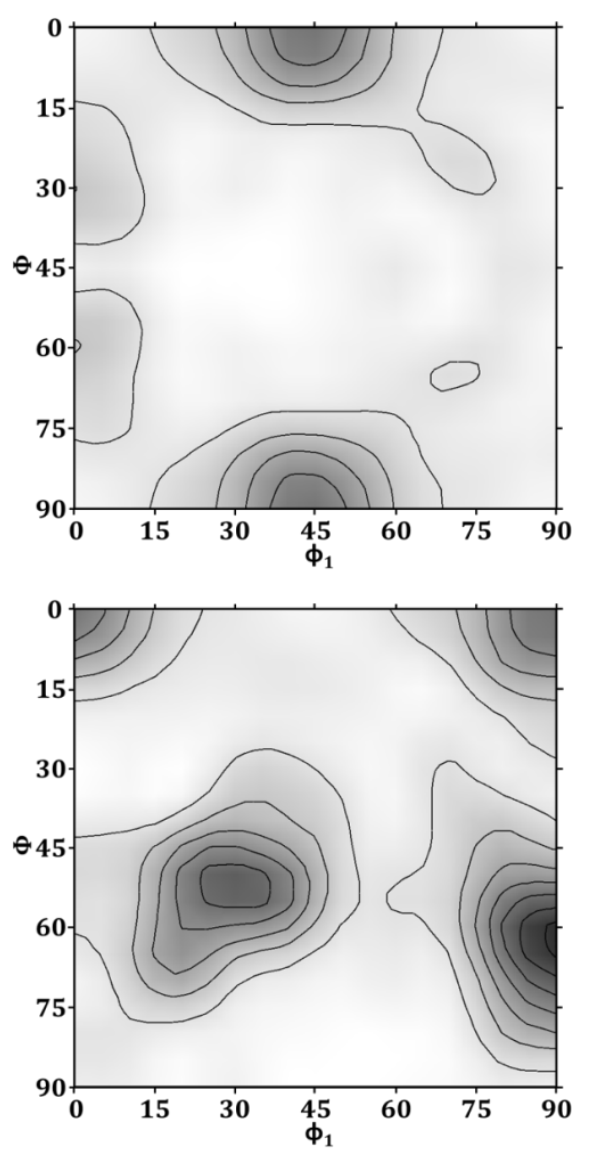

d
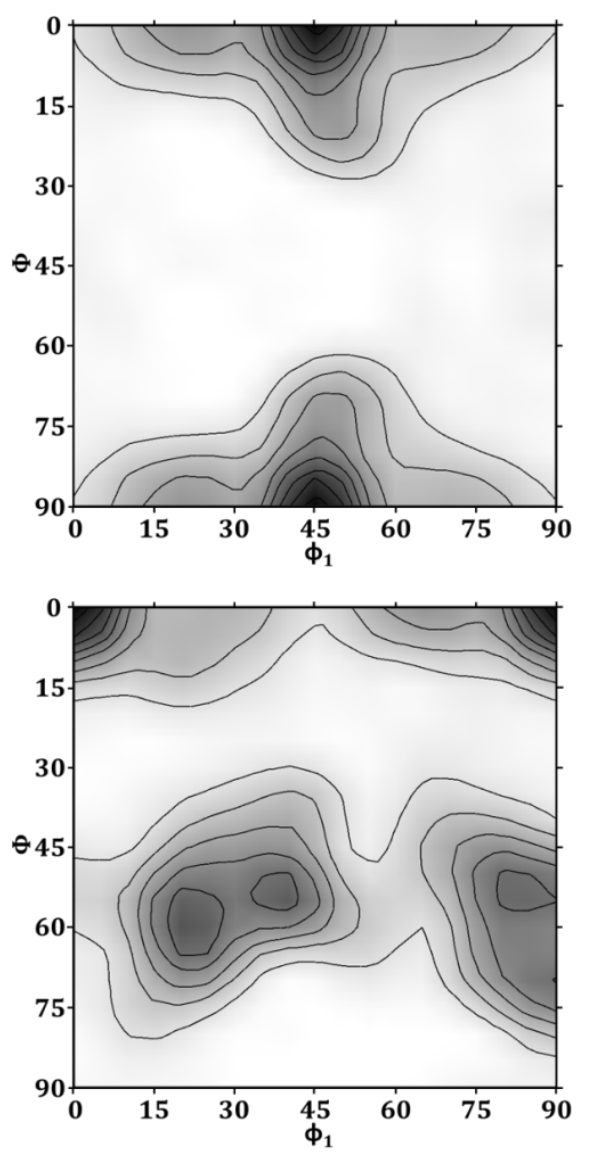

Figure 10. $\phi_{2}=0^{\circ}$ and $45^{\circ}$ ODF sections of (a) full map, (b) polygonal ferrite, (c) SIF and (d) second phase region in DT 750 sample from a scanning area of $180 \times 240$ $\mu \mathrm{m}^{2}$ (Fig. 7(f)). 
The texture of polygonal ferrite (Fig. 10(b)) mirrors that of the full map (Fig. 10(a)). While the polygonal ferrite and SIF textures are generally similar (c.f. Figs. 10(b, c)), higher intensity and less spread were observed for the latter. This is probably due to the preferential nucleation of SIF grains along the prior austenite grain boundaries following the K-S OR with at least one neighbouring parent austenite [36], as well as the limited growth of SIF [41, 42].

As pointed out in Refs. [41, 43], there is no strong evidence for variant selection during diffusional transformation, whereas variant selection typically occurs during diffusionless transformation. Consequently, while variant selection analysis is beyond the scope of the present study, it is expected to contribute to the observed differences between the ODFs of the diffusional and diffusionless transformation products as discussed below.

The higher texture intensities observed for the second phase regions (Fig. 10(d)) is likely due to the diffusionless transformation of austenite to bainite/martensite, which results in more intense textures than diffusional transformation [40, 41, 44]. Compared also to polygonal ferrite and SIF, the maximum intensity near the $\gamma$-fibre at $\phi_{1}=90^{\circ}$ shifts from (332)[ $\left.\overline{1} \overline{1} 3\right]$ towards (111)[ $[\overline{1} \overline{1} 2]$ in the second phase regions (Fig. 10(d)). Here both the (332)[ $\overline{1} \overline{1} 3]$ and (111)[ $\overline{1} \overline{1} 2]$ orientations originate from the $\mathrm{Br}$ component in austenite [41]. As reported in Ref. [15], during transformation from the $\mathrm{Br}$ Component, the (332)[1 $\overline{1} 3]$ orientation is favoured over the (111)[ $\overline{1} \overline{1} 2]$ orientation, when assuming equal probability of all the 24 possible variants of the K-S OR. It follows that, variant selection is likely responsible for the higher intensity of the (111)[ $\overline{1} \overline{1} 2]$ orientation compared to the (332)[ $\overline{1} \overline{1} 3]$ orientation (Fig. 10(d)) [41]. Additional point of difference between polygonal ferrite and SIF (Figs. 10(b, c)) on one 
hand and the second phase regions (Fig. 10(d)) on the other hand is the spread of the

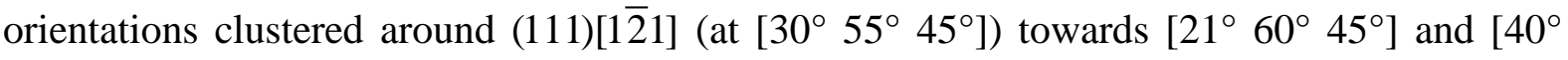
$54^{\circ} 45^{\circ}$. This shift in intensity can be ascribed to the transformation of stronger $\mathrm{S}$ and $\mathrm{G}$ components in the austenite fraction that undergoes diffusionless transformation to bainite/martensite, following the K-S OR [41, 43].

Lastly, the observation of weak orientations near (012)[100] (at [ $\left.0^{\circ} 30^{\circ} 0^{\circ}\right]$ ) and (021)[100] (at $\sim\left[0^{\circ} 60^{\circ} 0^{\circ}\right]$ ) only in polygonal ferrite and SIF (Figs. 10(b, c)) is likely associated with the presence of $\{103\}\langle 001\rangle$ orientations in the respective parent austenite grains.

\subsection{Mechanical properties}

Tensile curves after deformation at different temperatures are shown in Fig. 11, while the mechanical properties retrieved from these curves are listed in Table 3. Compared to the DT 800 and DT 750 samples, the DT 1050 and DT 700 samples showed higher $0.2 \%$ offset yield stress (YS) and ultimate tensile strength (UTS) with lower uniform elongation (UE) and total elongation (TE). This could be ascribed to the higher second phase regions fraction in the DT 1050 and DT 700 samples (Table 1). The optimal combination of strength and ductility was observed after deformation at $750{ }^{\circ} \mathrm{C}(\mathrm{UTS} \times \mathrm{TE}=18067 \mathrm{MPa} \%)$.

Table 3. Tensile properties after deformation at different temperatures.

\begin{tabular}{cccccc}
\hline & $\begin{array}{c}0.2 \% \text { offset } \\
\text { yield strength, } \\
\text { MPa }\end{array}$ & $\begin{array}{c}\text { Ultimate } \\
\text { tensile } \\
\text { strength, MPa }\end{array}$ & $\begin{array}{c}\text { Uniform } \\
\text { elongation }\end{array}$ & $\begin{array}{c}\text { Total } \\
\text { elongation }\end{array}$ & $\begin{array}{c}\text { Ultimate tensile strength } \times \\
\text { total elongation, MPa\% }\end{array}$ \\
\hline DT 700 & $416 \pm 12$ & $658 \pm 10$ & $0.10 \pm 0.001$ & $0.17 \pm 0.005$ & 11186 \\
DT 750 & $386 \pm 11$ & $623 \pm 7$ & $0.14 \pm 0.002$ & $0.29 \pm 0.002$ & 18067 \\
DT 800 & $401 \pm 14$ & $648 \pm 4$ & $0.14 \pm 0.004$ & $0.25 \pm 0.001$ & 16200 \\
DT 1050 & $477 \pm 11$ & $654 \pm 8$ & $0.08 \pm 0.002$ & $0.16 \pm 0.001$ & 10464 \\
\hline
\end{tabular}






Figure 11. Engineering stress-engineering strain curves after deformation at different temperatures.

\section{Discussion}

\subsection{Strain-induced ferrite formation}

The observation of SIF after deformation between 700 and $800{ }^{\circ} \mathrm{C}$ is in accordance with Refs. $[21,22]$, as this temperature range corresponds to the region from $\mathrm{Ar}_{3}$ to $\left(\mathrm{Ar}_{3}+100\right){ }^{\circ} \mathrm{C}$ where SIF formation is expected. The lowest SIF fraction $(0.03 \pm 0.01)$ obtained in DT 700 sample can be ascribed to the formation of proeutectoid ferrite before deformation, which occupies SIF nucleation sites along the prior austenite grain boundaries and consequently hinders SIF formation. Alternatively, the higher SIF fraction observed in DT 750 sample $(0.18 \pm 0.03)$ compared to DT 800 sample $(0.04 \pm 0.01)$ is attributed to the increase in driving force for ferrite nucleation with the decrease in deformation temperature [28, 45]. Thus, the following discussion is focused on the DT 750 sample with the largest SIF fraction.

An enlargement of the rectangular region in the DT 750 phase map (Fig. 7(f)) is given in Fig. 12(a) and it shows two groups of differently oriented SIF subgrains (marked by “A” and "B”) separated by a HAGB. Fig. 12(b) is a point-to-point misorientation profile along the white line in Fig. 12(a), which clearly shows the high misorientation $\left(\sim 46^{\circ}\right)$ across the boundary 
between A and B. Since SIF preferentially nucleate along prior austenite grain boundaries [28, 45, 46], groups A and B can be assumed to transform from two different prior austenite grains such that subgrains within the same group exhibit similar orientations and do not develop high misorientation angles (Fig. 12 (a)). This is likely linked to the limited coalescence and growth of SIF grains due to the high carbon concentration at the austenite/SIF and SIF/SIF interfaces, which in turn decreases the driving force for the interface migration [28]. Accordingly, high LAGB fraction is observed in the SIF subset (Table 2). Another potential reason for the observed high fraction of LAGBs is the occurrence of recovery (Fig. 6(c)) during slow cooling to $670{ }^{\circ} \mathrm{C}$ after deformation, leading to rearrangement of dislocation tangles.

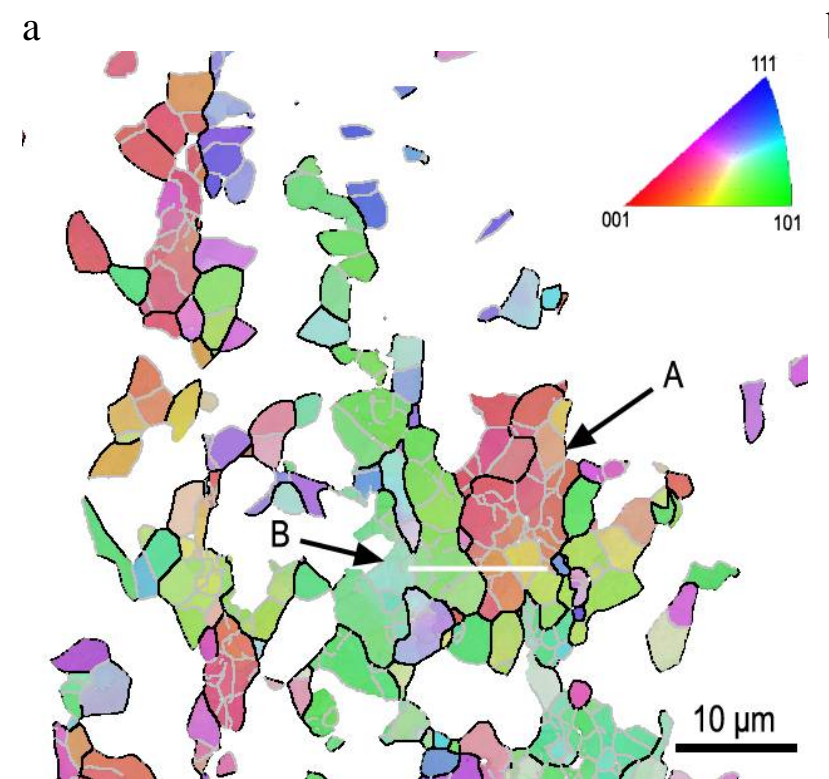

$\mathrm{b}$

Figure 12. (a) Inverse pole figure with grain boundaries of strain-induced ferrite after deformation at $750{ }^{\circ} \mathrm{C}$, which was enlarged from the rectangle region in Fig. 7(f); (b) corresponding point-to-point misorientation along the white line in (a) from left to right. LAGBs $=2-15^{\circ}=$ silver and HAGBs $\geq 15^{\circ}=$ black.

The high LAGB fraction observed in the present work after 0.41 reduction (Table 2) is in agreement with previous studies on low carbon [17] and DP steels [25], wherein similarly high LAGB fraction ( 0.50) was reported following a reduction range of $0.2-0.5$. In contrast, a low LAGB fraction ( 0.15) was recorded in Refs. [22, 47, 48] for a reduction of 
0.8. In the latter case, higher reductions reduce the LAGB fraction as the LAGBs formed during the initial stages of deformation progressively transform to HAGBs via subgrain rotation and dislocation incorporation into LAGBs [47, 49].

Depending on the deformation temperature, SIF formation may generally occur via diffusionless (>Ae 3 [27]) or diffusional (between $A r_{3}$ and $\left.A e_{3}[28,29]\right)$ transformation. Under the present experimental conditions (deformation between $A r_{3}\left(\approx 690{ }^{\circ} \mathrm{C}[10]\right)$ and $A e_{3}$ (around $\left.820-860{ }^{\circ} \mathrm{C}[22,25]\right)$ ) SIF is expected to form via diffusional transformation as supported by the following observations. Firstly, the misorientation angle distribution of SIF (Fig. 8) is markedly different from that of the second phase regions (forming via diffusionless transformation [34, 35, 38]) and is similar to that of polygonal ferrite (forming via diffusional transformation [28, 29]). Secondly, the TEM micrographs in Fig. 6, show similar dislocation substructures and recovery phenomenon in both SIF and polygonal ferrite. Lastly, the calculated deviations for each microstructure constituent from the ideal $\mathrm{K}-\mathrm{S}$ and $\mathrm{N}-\mathrm{W}$ ORs also suggest SIF formation by diffusional transformation. As seen in Fig. 13 and Table 4, the distributions and fractions of deviation angles for SIF are more similar to polygonal ferrite compared to the second phase regions.

To this end, Fig. 13 and Table 4 also indicate that phase transformation in the present study followed the K-S OR more closely than the N-W OR as evidenced by the higher fraction of low deviation angles (within $5^{\circ}$ ) for the former compared to the latter. In addition, SIF exhibited less deviation from the $\mathrm{K}-\mathrm{S}$ OR compared to polygonal ferrite due to its preferential nucleation along prior austenite grain boundaries (Fig. 7(f)) while following the K-S OR with at least one neighbouring parent austenite [36]. 

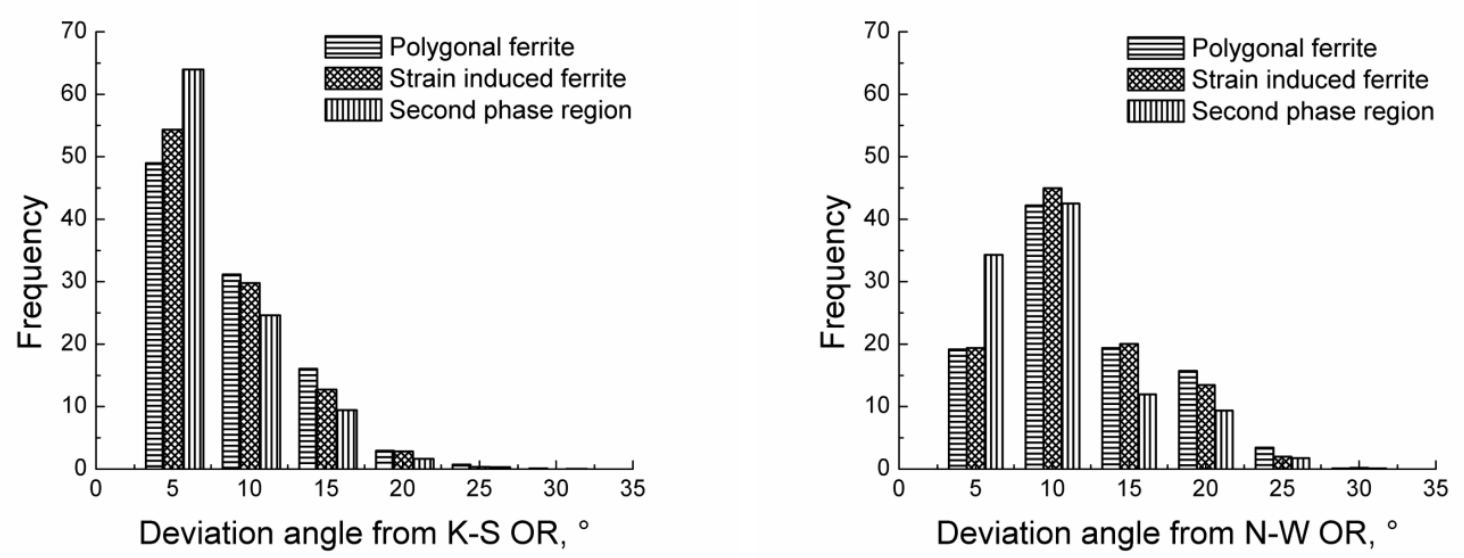

Figure 13 The distribution of deviation angles from (a) Kurdjumov-Sachs (K-S) and (b) Nishiyama-Wasserman (N-W) orientation relationships (ORs) for DT 750 sample.

Table 4. Fractions of deviation angles from the K-S and N-W ORs for the DT 750 sample. PF is polygonal ferrite, SIF is strain-induced ferrite and SPR is second phase region.

\begin{tabular}{ccccccc}
\hline & \multicolumn{3}{c}{ K-S OR } & \multicolumn{3}{c}{ N-W OR } \\
\cline { 2 - 7 } & SPR & PF & SIF & SPR & PF & SIF \\
\hline $0-5^{\circ}$ & 64 & 49 & 54 & 34 & 19 & 19 \\
$5-10^{\circ}$ & 25 & 31 & 30 & 43 & 42 & 45 \\
\hline
\end{tabular}

\subsection{The dependence of ferrite formation on deformation temperatures}

Understanding the effect of deformation temperature on ferrite nucleation and growth is of significant practical importance as the processing route in industrial strip casting lines comprises only one rolling mill $[4,6]$. The effect of deformation temperature on the nucleation and growth of ferrite in the present DP steel is schematically illustrated in Fig. 14 [22, 45, 47, 50, 51]. Deformation at $1050{ }^{\circ} \mathrm{C}$, which is above $T_{n r} \approx 950{ }^{\circ} \mathrm{C}[13,14,16]$, resulted in static recrystallisation, decreased PAGS and increased prior austenite grain boundary areas available for polygonal ferrite nucleation. Deformation at $950{ }^{\circ} \mathrm{C}$, which is near $T_{n r}$, resulted in pancaked austenite and elongated polygonal ferrite and second phase regions as seen in Fig. 2(b). The decrease in polygonal ferrite fraction from 0.63 to 0.53 (Table 1) with a decrease in deformation temperature from 1050 to $950{ }^{\circ} \mathrm{C}$ can be a consequence of a reduced number of nucleation sites in the pancaked austenite (at $950{ }^{\circ} \mathrm{C}$ ) 
with coarser grain size, compared to the recrystallised austenite (at $1050{ }^{\circ} \mathrm{C}$ ) with smaller grain size. With a decrease in deformation temperature to $850{ }^{\circ} \mathrm{C}$, the number of deformation-induced crystal defects increased, resulting in more nucleation sites not only along the prior austenite grain boundaries but also inside the grains [52], which led to an increase in polygonal ferrite fraction.


Figure 14. A schematic diagram of ferrite formation after different deformation temperatures.

After deformation at 800 and $750{ }^{\circ} \mathrm{C}$, the SIF formation first took place followed by polygonal ferrite formation. The total ferrite fraction increased due to a significant increase in the number of SIF nucleation sites along prior austenite grain boundaries where more deformation defects existed [26] and polygonal ferrite nucleation sites in the interior of prior austenite grains [52]. Both polygonal ferrite and SIF exhibited polygonal shape while the second phase regions were elongated following transformation from the deformed pancaked austenite (Figs. 2(d, e)). Decreasing the deformation to $700{ }^{\circ} \mathrm{C}$ decreased the total ferrite fraction from 0.81 to 0.70 (Table 1) as the time available for growth decreased. 
In accordance with the above discussion, the increase in the number of ferrite nucleation sites with decreasing deformation temperature leads to fine average ferrite grain size of $\sim 3 \mu \mathrm{m}$ (Table 1), following SIF formation.

\subsection{Mechanical properties}

The individual contribution of polygonal ferrite, SIF and second phase regions to the strain hardening is analysed by correlating the true stress $(\sigma)$ and true strain $(\varepsilon)$ of each microstructure constituent using the following equation $[53,54]$ :

$$
\sigma=\sigma_{0}+\Delta \sigma+\alpha \cdot \mu \cdot M \cdot \sqrt{b} \cdot \sqrt{\frac{1-\exp (-M k \varepsilon)}{k L}}
$$

where $\sigma_{0}$ considers the Peierls stress and solid solution strengthening as function of the weight percentages of substitutional alloying elements (taken here to be equal to the nominal chemical composition) [54]:

$$
\sigma_{0}=77+80[\mathrm{Mn}]+750[\mathrm{P}]+60[\mathrm{Si}]+80[\mathrm{Cu}]+60[\mathrm{Cr}]
$$

$\Delta \sigma$ represents the strengthening by carbon in solution. Considering the similarities between polygonal ferrite and SIF as shown in the above analysis, $\Delta \sigma$ is assumed to be the same for both constituents and calculated as [54]:

$\Delta \sigma=5000[C]$

For the second phase regions, $\Delta \sigma$ is expressed as [54]:

$$
\Delta \sigma=3065[C]-161
$$

For the three constituents, $\alpha$ is a material constant (0.33), $\mu$ is the shear modulus (80000 MPa), $M$ is the Taylor factor (3), $b$ is the Burger's vector $\left(2.5 \times 10^{-10} \mathrm{~m}\right), L$ is the mean free path of dislocations, and $k$ is the recovery rate $[54,55]$. For polygonal ferrite and SIF, $L$ was assumed to be equal to the average subgrain size determined from EBSD and $k$ is equal to $10^{-5} / L$. For the second phase regions, $L$ is an order of magnitude smaller than the lath width determined 
from EBSD and $k$ is set as 41 [54]. The carbon concentration [C] in polygonal ferrite and SIF was considered to be 0.004 wt. \% based on carbon solubility in iron at room temperature [56], whereas the carbon concentration in the second phase regions was calculated based on the carbon balance in the steel.

The modified iso-work model was used to correlate the true stress and true strain increments $(d \varepsilon)$ of each microstructure constituent [57]:

$\sigma_{P F} d \varepsilon_{P F}=\sigma_{S I F} d \varepsilon_{S I F}=w \sigma_{S P R} d \varepsilon_{S P R}$

where the subscripts $P F$, SIF and SPR denote polygonal ferrite, SIF and second phase regions, respectively, and $w$ is weighted constant for the second phase regions and is used as a fitting parameter.

The total macroscopic true strain increment $\left(d \varepsilon_{\text {macro }}\right)$ is given by rule of mixtures [58]:

$d \varepsilon_{\text {macro }}=f_{P F} d \varepsilon_{P F}+f_{S I F} d \varepsilon_{S I F}+f_{S P R} d \varepsilon_{S P R}$

where $f_{P F}, f_{S I F}$ and $f_{S P R}$ denote fractions of polygonal ferrite, SIF and second phase regions, respectively. The macroscopic true stress $\left(\sigma_{\text {macro }}\right)$ can be expressed as follows:

$$
\sigma_{\text {macro }}=f_{P F} \sigma_{P F}+f_{S I F} \sigma_{S I F}+f_{S P R} \sigma_{S P R}
$$

As seen in Fig. 15(a, b), the calculated macroscopic true stress-strain curves for the DT 750 and DT 800 samples are in a good agreement with their experimental counterparts. The slight overestimation in the elastic-plastic transition region is because the model does not account for elastic deformation [57].

As shown in Fig. 15(c) for the DT 750 sample, the strain hardening of the second phase regions reached a saturation level at a small strain of 0.02 , while more sustainable strain 
hardening was observed in both polygonal ferrite and SIF. The small grain size of SIF enhances the strength such that the calculated flow stress in SIF was $~ 80$ MPa higher than that in polygonal ferrite. At a macroscopic true strain of 0.140 (corresponding to the UTS), the true strains in polygonal ferrite, SIF and second phase regions were $0.160,0.139$ and 0.075, respectively, indicating that SIF formation slightly decreased ductility.

a

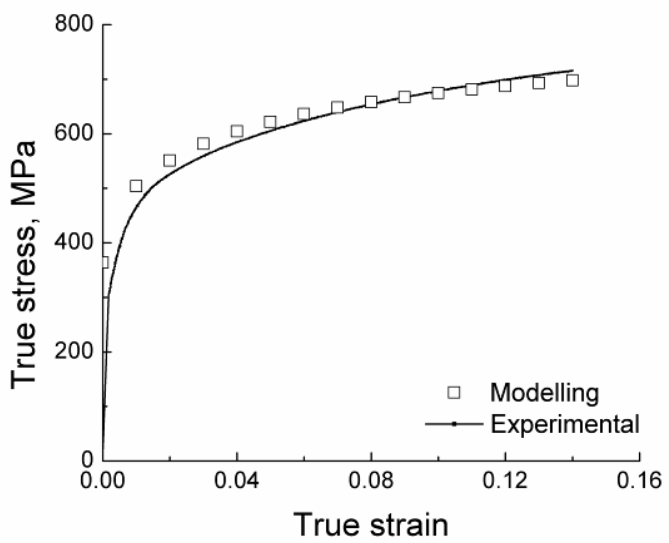

C

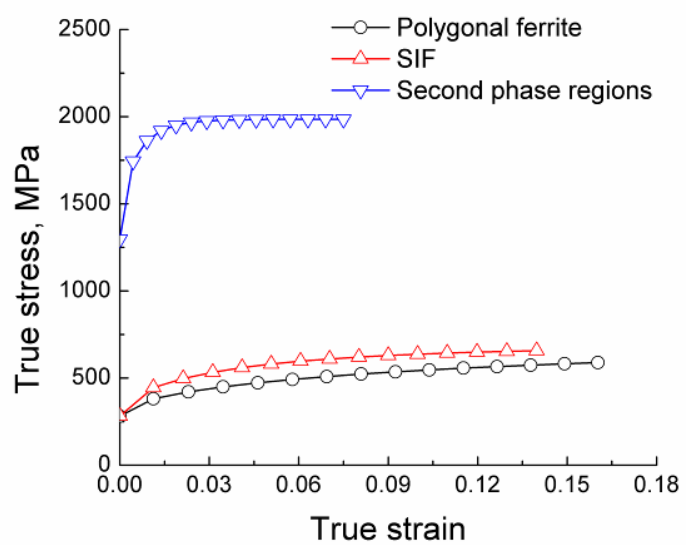

$\mathrm{b}$

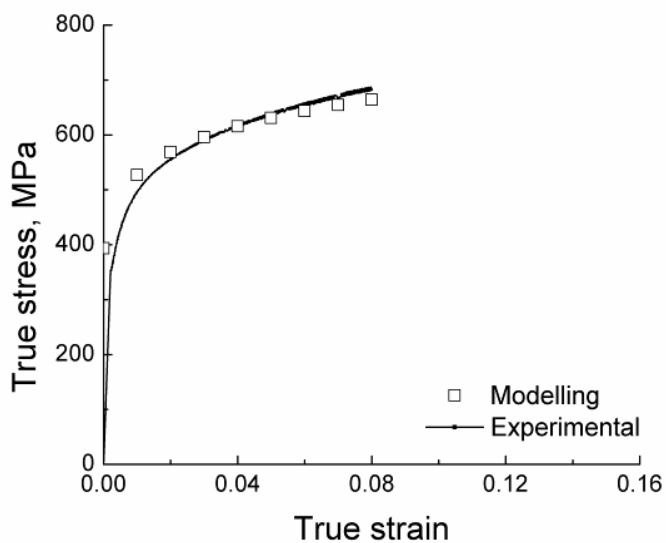

d

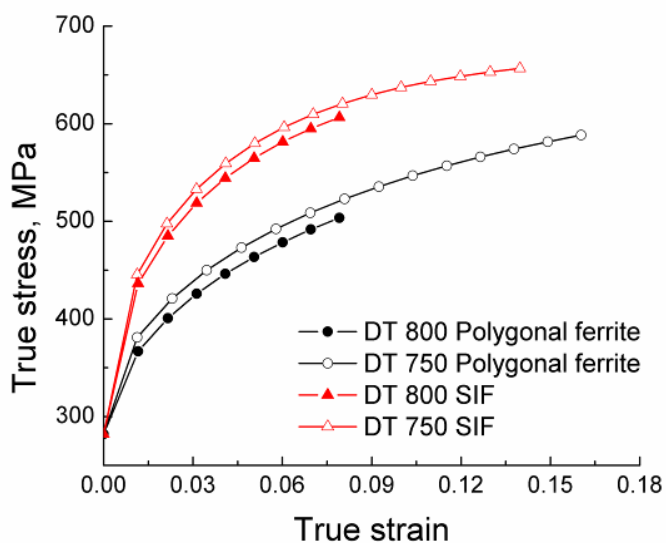

Figure 15. (a, b) Experimental true stress-strain curves and iso-work modelling results of (a) DT 750 and (b) DT 800 samples; (c) calculated true stress-strain curves for polygonal ferrite, strain-induced ferrite and second phase regions in DT 750 sample; (d) comparison of polygonal ferrite and strain-induced ferrite true stress-strain curves for the DT 750 and DT 800 samples. SIF is strain-induced ferrite.

Comparison of the true stress-strain curves of polygonal ferrite and SIF for the DT 750 and DT 800 samples (Fig. 15(d)) shows that both polygonal ferrite and SIF in DT 750 sample 
exhibited higher true stresses, which again resulted from smaller grain sizes in the DT 750 sample than those in the DT 800 sample (Table 1).

Lastly, the mechanical properties of the present strip cast DP steel are compared with those of commercially produced hot and cold rolled DP steels. The hollow stars in Fig. 16 show the mechanical properties of strip cast DP steel produced using heat treatment without deformation [11], while the half-hollow stars denote the improved mechanical properties as a result of deformation above the $T_{n r}$ temperature [10]. In the current study (solid stars) a further step in the property improvement was made via deformation below $T_{n r}$, namely in the $700-950{ }^{\circ} \mathrm{C}$ temperature range, a part of which led to SIF formation and significant grain refinement. The high ferrite fraction and refined microstructures of the DT 750 and DT 800 samples resulted in UTS $\times$ TE in the range of $16000-18000 \mathrm{MPa} \%$ (Fig. 16 and Table 3). These tensile properties significantly outperforms the industrially produced DP 600 steel (12760 - $14740 \mathrm{MPa} \%)$ and underscores the feasibility to produce DP steels using the strip casting technology. 




Figure 16 Comparison of mechanical properties among the studied steels [11, 12], hot rolled DP steels [5969] and DP steels from ArcelorMittal Company's brochure [70].

\section{Conclusions}

Investigation of the dependence of ferrite formation and mechanical properties on deformation temperature in strip cast dual phase steel showed that:

(1) With a decrease in deformation temperature from 1050 to $700{ }^{\circ} \mathrm{C}$, the ferrite fraction tended to increase, and the average ferrite grain size and the average size of second phase region tended to decrease. The SIF formation was observed following deformation in the 700 $-800{ }^{\circ} \mathrm{C}$ temperature range, with the maximum fraction and minimum grain size obtained at $750{ }^{\circ} \mathrm{C}$.

(2) Similar dislocation substructures, such as isolated dislocations, dislocation tangles and walls, were observed in SIF and polygonal ferrite. The dislocation walls suggested that the recovery phenomenon occurred during cooling after deformation.

(3) The textures observed after deformation in the temperature range $750-800{ }^{\circ} \mathrm{C}$ are typical steel hot rolling textures, which extends from the (111)[121] component through the 
(111)[0 $\overline{1} 1]$ to (332)[ $\overline{1} \overline{1} 3]$ along the $\gamma$-fibre. The SIF texture was more similar to polygonal ferrite than to the second phase regions.

(4) The similarity between various microstructure features (misorientation angle distributions, deviation from the theoretical $\mathrm{K}-\mathrm{S}$ and $\mathrm{N}-\mathrm{W}$ orientation relationships and dislocation structures) of SIF and polygonal ferrite suggests SIF formation via diffusional transformation. (5) The optimal combination of strength and ductility (UTS $\times$ TE) was obtained after deformation in the SIF formation temperature range of $750-800{ }^{\circ} \mathrm{C}$. Our present UTS $\times$ TE values (16000 - $18000 \mathrm{MPa} \%)$ are much higher than those of industrially manufactured hot/cold rolled DP 600 steel (12760 - $14740 \mathrm{MPa} \%)$.

(6) The modified iso-work modelling analysis of the flow stress suggests that SIF could enhance strength while slightly decreasing ductility.

\section{Acknowledgement:}

This project was supported by the Australian Research Council (DP130101887). The JEOL JSM-7001F FEG-SEM was funded by the Australian Research Council (LE0882613). The authors thank Drs. A.A. Gazder and L. Chen, UOW for modification of tensile stage and operation of the Gleeble 3500 thermo-mechanical simulator, respectively. The authors also thank Associate Professor N.E. Stanford in Monash University for the dip tests.

\section{References:}

[1] R. Kuziak, R. Kawalla, S. Waengler, Advanced high strength steels for automotive industry, Arch. Civ. Mech. Eng. 8 (2008) 103-117.

[2] C.C. Tasan, M. Diehl, D. Yan, M. Bechtold, F. Roters, L. Schemmann, C. Zheng, N. Peranio, D. Ponge, M. Koyama, K. Tsuzaki, D. Raabe, An Overview of Dual-Phase Steels: Advances in Microstructure-Oriented Processing and Micromechanically Guided Design, Annu. Rev. Mater. Res. 45 (2015) 391-431.

[3] A.P. Hardwick, T. Outteridge, Vehicle lightweighting through the use of molybdenumbearing advanced high-strength steels (AHSS), Int. J. Life Cycle Assess. 21 (2016) 16161623. 
[4] D.J. Sosinsky, P. Campbell, R. Mahapatra, W. Blejde, F. Fisher, The CASTRIP processrecent developments at Nucor steel's commercial strip casting plant, Metallurgist 52 (2008) 691-699.

[5] H.Y. Gao, Z.X. Xie, Y. Yu, Y. Fang, J. Wang, B.D. Sun, Dynamic recrystallization behavior of twin roll cast low carbon steel strip, ISIJ Int. 49 (2009) 546-552.

[6] C.R. Killmore, A. Phillips, H. Kaul, J.C. Williams, H. Creely, P. Campbell, M.M. Schueren, W. Blejde, Development of ultrathin cast strip products by the CASTRIP process, Iron Steel Technol. 4 (2007) 90-105.

[7] S. Ge, M. Isac, R.I.L. Guthrie, Progress of strip casting technology for steel; historical development, ISIJ Int. 52 (2012) 2109-2122.

[8] M. Daamen, C. Haase, J. Dierdorf, D.A. Molodov, G. Hirt, Twining roll casting: A competitive alternative for the production of high-manganese steels with advanced mechanical properties, Mater. Sci. Eng. A 627 (2015) 72-81.

[9] Z.P. Xiong, A.G. Kostryzhev, A.A. Saleh, L. Chen, E.V. Pereloma, Microstructures and mechanical properties of TRIP steel produced by strip casting simulated in the laboratory, Mater. Sci. Eng. A 664 (2016) 26-42.

[10] Z.P. Xiong, A.G. Kostryzhev, N.E. Stanford, E.V. Pereloma, Effect of deformation on microstructure and mechanical properties of dual phase steel produced via strip casting simulation, Mater. Sci. Eng. A 651 (2016) 291-305.

[11] Z.P. Xiong, A.G. Kostryzhev, N.E. Stanford, E.V. Pereloma, Microstructures and mechanical properties of dual phase steel produced by laboratory simulated strip casting, Mater. Des. 88 (2015) 537-549.

[12] D. Raabe, Textures of strip cast and hot rolled ferritic and austenitic stainless steel, Mater. Sci. Tech. 11 (1995) 461-468.

[13] M. Arribas, B. López, J. Rodriguez-Ibabe, Additional grain refinement in recrystallization controlled rolling of Ti-microalloyed steels processed by near-net-shape casting technology, Mater. Sci. Eng. A 485 (2008) 383-394.

[14] S. Hosseini, A. Zarei-Hanzaki, E. Essadiqi, S. Yue, Effect of prior austenite characteristics on mechanical properties of thermomechanically processed multiphase TRIP assisted steels, Mater. Sci. Technol. 24 (2008) 1354-1361.

[15] M. Butron-Guillen, J. Jonas, R. Ray, Effect of austenite pancaking on texture formation in a plain carbon and a Nb microalloyed steel, Acta Metall. Mater. 42 (1994) 3615-3627.

[16] S. Vervynckt, K. Verbeken, B. Lopez, J. Jonas, Modern HSLA steels and role of nonrecrystallisation temperature, Int. Mater. Rev. 57 (2012) 187-207.

[17] P.J. Hurley, P. Hodgson, B. Muddle, Analysis and characterisation of ultra-fine ferrite produced during a new steel strip rolling process, Scripta Mater. 40 (1999) 433-438.

[18] L. Storojeva, D. Ponge, R. Kaspar, D. Raabe, Development of microstructure and texture of medium carbon steel during heavy warm deformation, Acta Mater. 52 (2004) 2209-2220.

[19] M. Calcagnotto, D. Ponge, D. Raabe, Microstructure control during fabrication of ultrafine grained dual-phase steel: characterization and effect of intercritical annealing parameters, ISIJ Int. 52 (2012) 874-883.

[20] M. Calcagnotto, D. Ponge, D. Raabe, Ultrafine grained ferrite/martensite dual phase steel fabricated by large strain warm deformation and subsequent intercritical annealing, ISIJ Int. 48 (2008) 1096-1101.

[21] L. Du, C. Zhang, H. Ding, X. Liu, G. Wang, Determination of upper limit temperature of strain-induced transformation of low carbon steels, ISIJ Int. 42 (2002) 1119-1124.

[22] A. Karmakar, R. Misra, S. Neogy, D. Chakrabarti, Development of ultrafine-grained dual-phase steels: mechanism of grain refinement during intercritical deformation, Metall. Mater. Trans. A 44 (2013) 4106-4118. 
[23] P. Hurley, P. Hodgson, Effect of process variables on formation of dynamic strain induced ultrafine ferrite during hot torsion testing, Mater. Sci. Technol. 17 (2001) 1360-1368. [24] P. Hurley, P. Hodgson, Formation of ultra-fine ferrite in hot rolled strip: potential mechanisms for grain refinement, Mater. Sci. Eng. A 302 (2001) 206-214.

[25] K. Mukherjee, S. Hazra, M. Militzer, Grain refinement in dual-phase steels, Metall. Mater. Trans. A 40 (2009) 2145-2159.

[26] S.C. Hong, K.S. Lee, Influence of deformation induced ferrite transformation on grain refinement of dual phase steel, Mater. Sci. Eng. A 323 (2002) 148-159.

[27] C. Ghosh, V.V. Basabe, J.J. Jonas, Y.M. Kim, I.H. Jung, S. Yue, The dynamic transformation of deformed austenite at temperatures above the $\mathrm{Ae}_{3}$, Acta Mater. 61 (2013) 2348-2362.

[28] C. Zheng, N. Xiao, L. Hao, D. Li, Y. Li, Numerical simulation of dynamic straininduced austenite-ferrite transformation in a low carbon steel, Acta Mater. 57 (2009) 29562968.

[29] C.W. Zheng, D. Raabe, D.Z. Li, Numerical simulation of dynamic strain-induced austenite-ferrite transformation and post-dynamic kinetics in a low carbon steel, Mater. Sci. Forum 706-709 (2012) 1592-1597.

[30] H. Yada, C.M. Li, H. Yamagata, Dynamic $\gamma \rightarrow \alpha$ transformation during hot deformation in iron-nickel-carbon alloys, ISIJ Int. 40 (2000) 200-206.

[31] K. Mukunthan, P.D. Hodgson, P. Sellamuthu, L. Strezov, Y. Durandet, N. Stanford, Castability and microstructural development of iron-based alloys under conditions pertinent to strip casting - specialty Fe-Cr-Al alloys, ISIJ Int. 53 (2013) 1803-1811.

[32] G. Palumbo, K.T. Aust, Structure-dependence of intergranular corrosion in high purity nickel, Acta Metall. Mater. 38 (1990) 2343-2352.

[33] R. Hielscher, H. Schaeben, A novel pole figure inversion method: specification of the MTEX algorithm, J. Appl. Crystallogr. 41 (2008) 1024-1037.

[34] N. Takayama, G. Miyamoto, T. Furuhara, Effects of transformation temperature on variant pairing of bainitic ferrite in low carbon steel, Acta Mater. 60 (5) (2012) 2387-2396.

[35] H. Beladi, Y. Adachi, I. Timokhina, P.D. Hodgson, Crystallographic analysis of nanobainitic steels, Scripta Mater. 60 (2009) 455-458.

[36] E. Novillo, D. Hernandez, I. Gutierrez, B. Lopez, Analysis of ferrite grain growth mechanisms during $\gamma-\alpha$ transformation in a niobium alloyed steel using EBSD, Mater. Sci. Eng. A 385 (2004) 83-90.

[37] J.J. Fundenberger, B. Beausir, Université de Lorraine - Metz, 2015, JTEX - Software for Texture Analysis, http://jtex-software.eu/.

[38] L. Ryde, Application of EBSD to analysis of microstructures in commercial steels, Mater. Sci. Technol. 22 (2006) 1297-1306.

[39] A.A. Gazder, A.A. Saleh, M.J.B. Nancarrow, D.R.G. Mitchell, E.V. Pereloma, A transmission kikuchi diffraction study of a cold-rolled and annealed Fe-17Mn-2Si-3Al-1Ni0.06C wt\% Steel, Steel Res. Int. 86 (2015) 1204-1214.

[40] C. Mesplont, B. De Cooman, Effect of austenite deformation on crystallographic texture during transformations in microalloyed bainitic steel, Mater. Sci. Technol. 19 (2003) 875-886. [41] R. Ray, J. Jonas, Transformation textures in steels, Int. Mater. Rev. 35 (1990) 1-36.

[42] C. Ghosh, C. Aranas Jr, J.J. Jonas, Dynamic transformation of deformed austenite at temperatures above the $\mathrm{Ae}_{3}$, Prog. Mater. Sci. 82 (2016) 151-233.

[43] T. Waterschoot, L. Kestens, B. De Cooman, Hot rolling texture development in CMnCrSi dual-phase steels, Metall. Mater. Trans. A 33 (2002) 1091-1102.

[44] B. Hutchinson, L. Ryde, E. Lindh, K. Tagashira, Texture in hot rolled austenite and resulting transformation products, Mater. Sci. Eng. A 257 (1998) 9-17. 
[45] X. Sun, H. Luo, H. Dong, Q. Liu, Y. Weng, Microstructural evolution and kinetics for post-dynamic transformation in a plain low carbon steel, ISIJ Int. 48 (2008) 994-1000.

[46] S. Wang, H. Yu, T. Zhou, T. Wang, Effects of non-recrystallization zone reduction on microstructure and precipitation behavior of a ferrite-bainite dual phase steel, Mater. Des. 88 (2015) 847-853.

[47] L. Hao, M. Sun, N. Xiao, D. Li, Characterizations of dynamic strain-induced transformation in low carbon steel, J. Mater. Sci. Technol. 28 (2012) 1095-1101.

[48] B. Eghbali, A. Abdollah-Zadeh, Strain-induced transformation in a low carbon microalloyed steel during hot compression testing, Scripta Mater. 54 (2006) 1205-1209.

[49] G.L. Kelly, H. Beladi, P.D. Hodgson, Ultrafine grained ferrite formed by interrupted hot torsion deformation of plain carbon steel, ISIJ Int. 42 (2002) 1585-1590.

[50] B. Eghbali, A. Abdollah-Zadeh, Influence of deformation temperature on the ferrite grain refinement in a low carbon Nb-Ti microalloyed steel, J. Mater. Process. Technol. 180 (2006) 44-48.

[51] C. Zhang, M. Zhang, T. Guo, J. Yang, Y. Kong, D. Cai, Q. Li, Ferrite grain refinement in low carbon $\mathrm{Cu}-\mathrm{P}-\mathrm{Cr}-\mathrm{Ni}-\mathrm{Mo}$ weathering steel at various temperatures in the $(\alpha+\gamma)$ region, Mater. Charact. 113 (2016) 10-16.

[52] N. Xiao, M. Tong, Y. Lan, D. Li, Y. Li, Coupled simulation of the influence of austenite deformation on the subsequent isothermal austenite-ferrite transformation, Acta Mater. 54 (2006) 1265-1278.

[53] Y. Estrin, H. Mecking, A unified phenomenological description of work hardening and creep based on one-parameter models, Acta Metall. 32 (1984) 57-70.

[54] R.M. Rodriguez, I. Gutiérrez, Unified formulation to predict the tensile curves of steels with different microstructures, Mater. Sci. Forum 426-432 (2003) 4525-4530.

[55] A. Ramazani, K. Mukherjee, A. Abdurakhmanov, U. Prahl, M. Schleser, U. Reisgen, W. Bleck, Micro-macro-characterisation and modelling of mechanical properties of gas metal arc welded (GMAW) DP600 steel, Mater. Sci. Eng. A 589 (2014) 1-14.

[56] A. Ramazani, P.T. Pinard, S. Richter, A. Schwedt, U. Prahl, Characterisation of microstructure and modelling of flow behaviour of bainite-aided dual-phase steel, Comput. Mater. Sci. 80 (2013) 134-141.

[57] S.K. Paul, M. Mukherjee, Determination of bulk flow properties of a material from the flow properties of its constituent phases, Comput. Mater. Sci. 84 (2014) 1-12.

[58] E.J. Seo, L. Cho, Y. Estrin, B.C. De Cooman, Microstructure-mechanical properties relationships for quenching and partitioning (Q\&P) processed steel, Acta Mater. 113 (2016) 124-139.

[59] E. Ahmad, T. Manzoor, N. Hussain, N. Qazi, Effect of thermomechanical processing on hardenability and tensile fracture of dual-phase steel, Mater. Des. 29 (2008) 450-457.

[60] K. Park, M. Nishiyama, N. Nakada, T. Tsuchiyama, S. Takaki, Effect of the martensite distribution on the strain hardening and ductile fracture behaviors in dual-phase steel, Mater. Sci. Eng. A 604 (2014) 135-141.

[61] M. Calcagnotto, Y. Adachi, D. Ponge, D. Raabe, Deformation and fracture mechanisms in fine-and ultrafine-grained ferrite/martensite dual-phase steels and the effect of aging, Acta Mater. 59 (2011) 658-670.

[62] T. Wen, H. Bin, S. Wang, Y. Yi, C. Zhang, Y. Zhang, Effects of TMCP parameters on microstructure and mechanical properties of hot rolled economical dual phase steel in CSP, J. Iron Steel Res. Int. 19 (2012) 37-41.

[63] P. Deb, M. Chaturvedi, Influence of thermomechanical treatment on the structureproperty relationship of a microalloyed dual-phase high strength, Low Alloy Steel, Mater. Sci. Eng. 78 (1986) L7-L13. 
[64] J. Hu, L.X. Du, J.J. Wang, C.R. Gao, T.Z. Yang, A.Y. Wang, R. Misra, Microstructures and mechanical properties of a new as-hot-rolled high-strength DP steel subjected to different cooling schedules, Metall. Mater. Trans. A 44 (2013) 4937-4947.

[65] N. Kolbasnikov, Y.A. Bezobrazov, A. Naumov, Structural evolution of high-strength dual-phase steel in hot rolling, Steel Transl. 43 (2013) 455-459.

[66] J. Lis, A. Lis, C. Kolan, Processing and properties of C-Mn steel with dual-phase microstructure, J. Mater. Process. Technol. 162 (2005) 350-354.

[67] A. Panda, P. Ray, R. Ganguly, Effect of thermomechanical treatment parameters on mechanical properties of duplex ferrite-martensite structure in dual phase steel, Mater. Sci. Technol. 16 (2000) 648-656.

[68] X. Xu, J. Kong, J. Lin, R. Zheng, Study on a rolling process for obtaining ferritemartensitic (DP) microstructures in ER70S-6 steel, Rev. Adv. Mater. Sci 33 (2013) 348-353.

[69] R. González, J. García, L. Verdeja, M. Quintana, J. Verdeja, Mechanical behaviour of thermomechanically produced ultrafine grained dual-phase steels, Can. Metall. Q. 53 (2014) 100-106.

[70] http://automotive.arcelormittal.com/europe/products/AHSS/EN. 